Portland State University

PDXScholar

$5-13-2008$

\title{
The Role of Mitochondria ATP-sensitive Potassium Channel in Cardioprotection
}

Ksenia Andrukhiv Everton

Portland State University

Follow this and additional works at: https://pdxscholar.library.pdx.edu/open_access_etds

Part of the Biology Commons

Let us know how access to this document benefits you.

\section{Recommended Citation}

Everton, Ksenia Andrukhiv, "The Role of Mitochondria ATP-sensitive Potassium Channel in Cardioprotection" (2008). Dissertations and Theses. Paper 5829.

https://doi.org/10.15760/etd. 7700

This Thesis is brought to you for free and open access. It has been accepted for inclusion in Dissertations and Theses by an authorized administrator of PDXScholar. Please contact us if we can make this document more accessible: pdxscholar@pdx.edu. 


\section{THESIS APPROVAL}

The abstract and thesis of Ksenia Andrukhiv Everton for the Master of Science in

Biology were presented on May 13,2008, and accepted by the thesis committee and the department.

COMMITTEE APPROVALS:

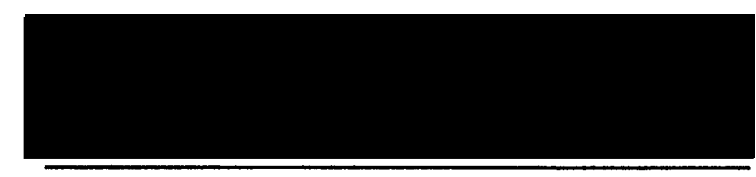

Keith Garlid, Chair

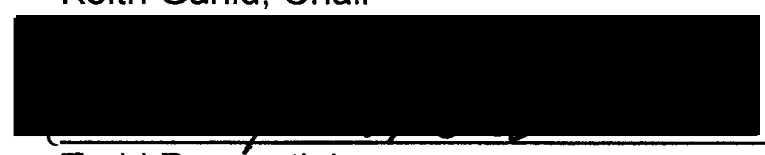

Todd Rosenstiel

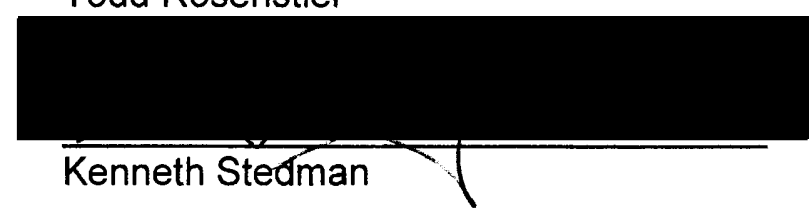

DEPARTMENT APPROVAL:

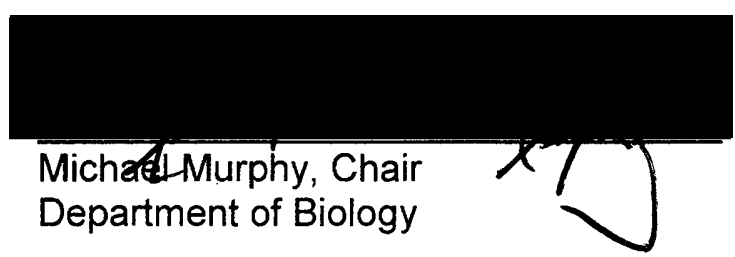




\section{ABSTRACT}

An abstract of the thesis of Ksenia Andrukhiv Everton for the Master of Science in Biology presented on May 13, 2008.

Title: The role of mitochondrial ATP-sensitive potassium channel in cardioprotection.

Mitochondrial ATP-sensitive potassium channel (mitoK $\mathrm{ATP}_{\text {) }}$ has been suggested to be the mediator of cardiac preconditioning. All of the diverse pharmacological and physiological agents that open mitoK $\mathrm{K}_{\mathrm{ATP}}$ provide protection against ischemia-reperfusion injury. Some investigators have pointed out that some of these mitoK $\mathrm{ATP}_{\mathrm{P}}$ channel openers also inhibit succinate dehydrogenase (SDH), complex II of the electron transport chain. Based on this observation they suggest that it is the inhibition of $\mathrm{SDH}$, and not the opening of mitoK $\mathrm{ATP}_{\mathrm{P}}$ channel, that mediates the observed cardioprotection. In this study, I examined four chemically distinct and unrelated pharmacological agents, diazoxide, 3-Nitropropionic Acid (3-NPA), Protein Kinase G (PKG), and $\Psi_{\varepsilon R A C K}$, all of which have been shown to open mitoK $K_{\text {ATP }}$, to demonstrate that the said cardioprotective effect mediated by mitoK $\mathrm{K}_{\text {ATP }}$ is entirely independent of SDH. Light scattering technique was utilized to measure the 


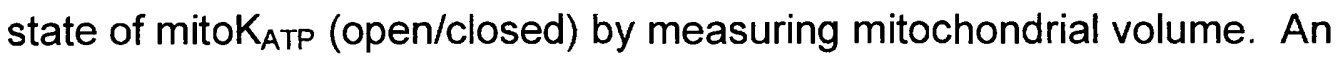
electrode that measures oxygen concentration was utilized to measure mitochondrial respiration. The results of this study confirm that two of the drugs, diazoxide and 3-NPA, inhibit succinate-supported respiration in high doses $(I C 50=140 \mu \mathrm{M}$ and IC50 $=1.05 \mathrm{mM}$, respectively $)$. Both of these drugs, however, do not inhibit succinate-supported respiration at the concentration necessary to open mitoK $\mathrm{ATP}(30 \mu \mathrm{M}$ and $10 \mathrm{nM}$, respectively). PKG and

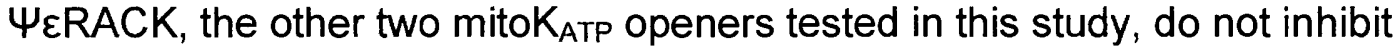
succinate-supported respiration at any concentration tested. These results support the hypothesis that potassium channel openers mediate cardioprotection through the opening of mitoK $\mathrm{ATP}_{\mathrm{P}}$ and not through the inhibition of SDH. 
THE ROLE OF MITOCHONDRIA ATP-

SENSITIVE POTASSIUM CHANNEL IN CARDIOPROTECTION

by

KSENIA ANDRUKHIV EVERTON

A thesis submitted in partial fulfillment of the requirements for the degree of

\section{MASTER OF SCIENCE \\ in \\ BIOLOGY}

Portland State University

2008 


\section{ACKNOWLEDGMENTS}

This work was done in the laboratory of Dr. Keith Garlid at Portland State University. I am grateful to Dr. Garlid for giving me the opportunity and providing the resources to do this work.

I would like to thank all of the members of the Garlid lab, present and past, for their help and assistance throughout my time at Portland State University. Especially, l'd like to thank Craig Semrad and Casey Quinlan for their continual patience, support, and willingness to help me.

Also, I would like to thank my committee members, Todd Rosenstiel and Kenneth Stedman for their willingness to participate on this committee and their time. In addition, l'd like to thank Todd Rosenstiel for his insights and continual support. Finally, I would like to thank my family, my parents, sisters, and especially my husband, for all their love and encouragement throughout my time at PSU.

This study was supported by NIH grant to Keith Garlid. 


\section{TABLE OF CONTENTS}

\section{ACKNOWLEDGMENTS}

LIST OF FIGURES

iv

LIST OF ABBREVIATIONS $\ldots \ldots \ldots \ldots \ldots \ldots \ldots \ldots \ldots \ldots$

1. Introduction and Literature Review $\ldots \ldots \ldots \ldots \ldots \ldots \ldots \ldots \ldots$

1.1 Heart Attacks and Infarct $\ldots \ldots \ldots \ldots \ldots \ldots \ldots \ldots \ldots$

1.2 Normoxic Mitochondria . . . . . . . . . . . . . . . . . 2

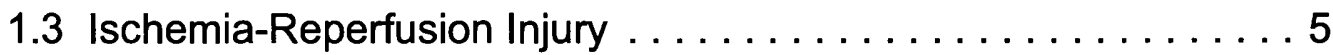

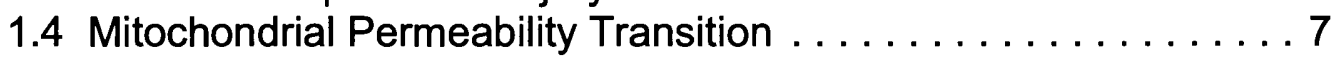

1.5 Ischemic Preconditioning $\ldots \ldots \ldots \ldots \ldots \ldots \ldots \ldots \ldots$

1.6 Modes of Protection . . . . . . . . . . . . . . . . . 9

1.7 Cardioprotection by Potassium Channel Openers

1.8 MitoK $_{\text {ATP }}$ Mediates Cardioprotection by KCOs $\ldots \ldots \ldots \ldots \ldots 10$

1.9 MitoK $_{\text {ATP }}$ During Normal Conditions $\ldots \ldots \ldots \ldots \ldots \ldots \ldots 12$

1.9.a MitoK $_{\text {ATP }}$ in normal cell signaling .............. 12

1.9.b MitoK $K_{A T P}$ opening in high work state - maintenance of positive ionotropy ........................ 13

1.10 MPT and mitoK $_{\text {ATP }} \ldots \ldots \ldots \ldots \ldots \ldots \ldots \ldots \ldots \ldots \ldots$

1.11 Mechanism of Cardioprotection Induced by MitoK $\mathrm{K}_{\mathrm{ATP}}$

1.12 MitoK $_{\text {ATp }}$ in Other Tissues .......................... 19

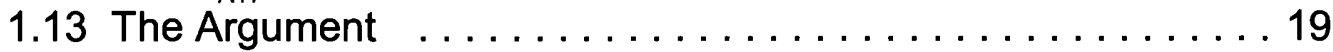

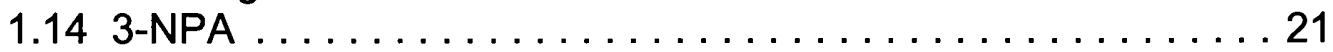

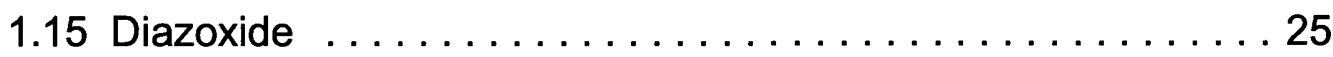

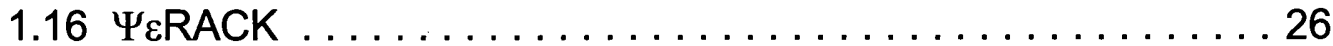

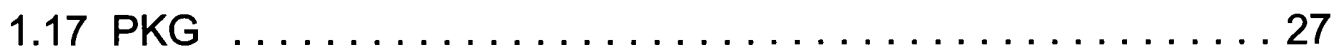

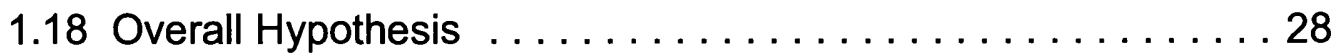

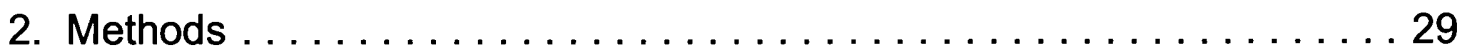

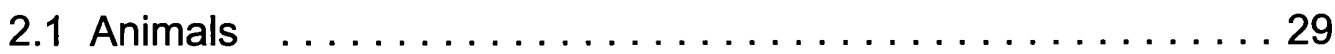

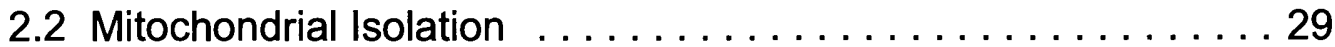

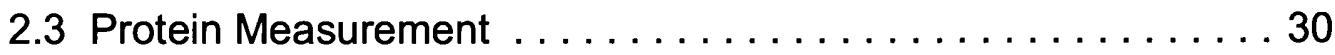

2.4 Measurement of Mitochondrial Volume ........... 30

2.5 Measurement of Mitochondrial Respiration .......... 32

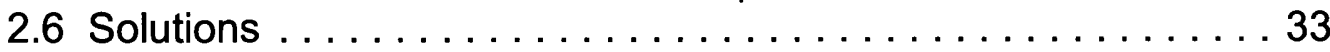

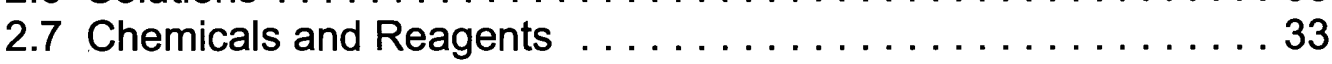

2.8 Data Analysis . . . . . . . . . . . . . . . 33 


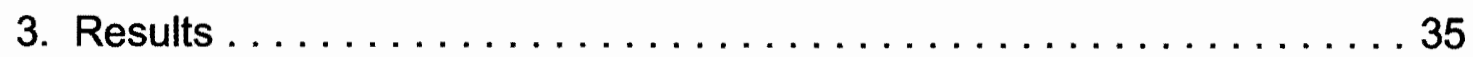

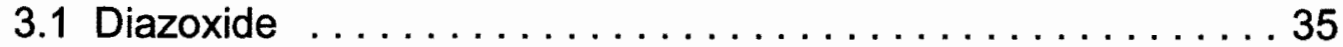

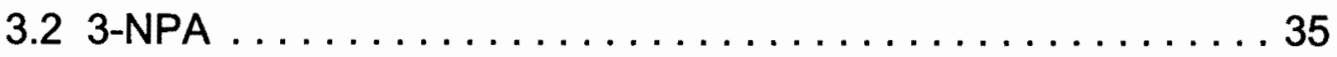

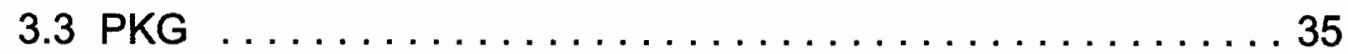

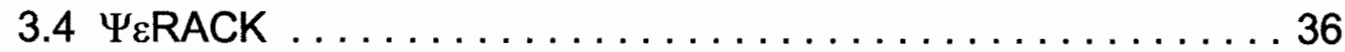

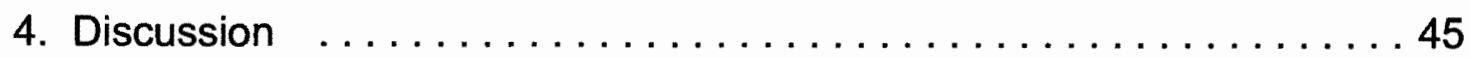

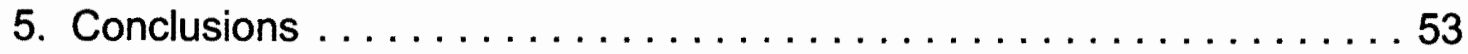

6. References $\ldots \ldots \ldots \ldots \ldots \ldots \ldots \ldots \ldots \ldots \ldots \ldots \ldots \ldots$ 


\section{LIST OF FIGURES}

1 Internal Structures of Normoxic Mitochondria..............................4

2 The Cardioprotective Signaling Pathway in Mitochondria............17

3 Molecular Structure of 3-NPA ....................................... 21

4 Mechanism by which 3-NPA Deactivates SDH...................24

5 Molecular Structure of Diazoxide ..................................25

$6 \quad$ Diazoxide Opens mitoKATP ....................................... 37

$7 \quad$ Diazoxide Inhibits Respiration......................................38

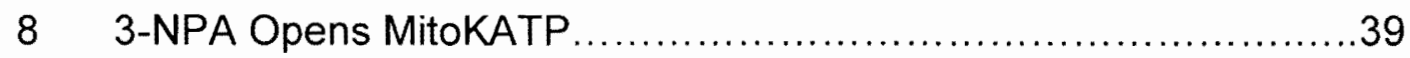

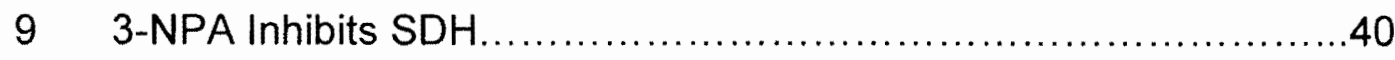

10a PKG Does Not Inhibit Respiration................................. 41

10b PKG + cGMP Do Not Inhibit Respiration (traces) ..................42

11a $\Psi \varepsilon R A C K$ Does Not Inhibit Respiration..................................43

11b $\Psi \varepsilon R A C K$ Does Not Inhibit Respiration (traces).......................44 


\section{LIST OF ABBREVIATIONS}

3-NPA

5-HD

ADP

AIF

APD

ATP

CGMP

CPC

IMS

IPC

$\mathrm{KCOs}$

MitoK $_{\text {ATP }}$

MPT

NHE

PKC

PKG

PMA

ROS

sarcK $_{\text {ATP }}$

$\mathrm{SDH}$

VDAC
3-Nitropropionic Acid

5-hydroxydecanoate

Adenosine diphosphate

Apoptose-inducing Factor

Action potential duration

Adenosine triphosphate

Cyclic guanylyl monophosphate

Calcium preconditioning

Inter-membrane space

Ischemic preconditioning

Potassium channel openers

Mitochondrial ATP-sensitive potassium

channel

Mitochondrial Permeability Transition Pore

Sodium Hydrogen Exchanger

Protein Kinase $C$

Protein Kinase G (cGMP-dependent protein kinase)

Phorbol 12-myristate 13-acetate

Reactive Oxygen Species

Sarcoplasmic ATP-sensitive potassium

channel

Succinate Dehydrogenase (Complex II)

Voltage-dependent ion channel 


\section{Introduction and Literature Review}

\subsection{Heart Attacks and Infarct}

Heart attacks and their associated complications are the number one cause of death in the United States and worldwide. According to the American Heart Association there are over a million new and recurrent coronary attacks per year, and of these about 38 percent will result in death [1]. In addition, World Health Organization reported that acute myocardial infarction is the leading cause of death throughout the world in both men and women. During coronary thrombosis, commonly associated with atherosclerotic plaque in blood vessels, blood flow through the circulatory system is obstructed resulting in lack of nutrients and oxygen to the heart. Prolonged lack of nutrition may lead to tissue death, also known as infarction. Infarction and other known damage-causing aspects of a heart attack are induced by apoptotic and necrotic cell death mechanisms. This tissue damage is irreversible and begins within approximately 20 minutes of occlusion. Because infarcted tissue cannot regenerate and thus permanently decreases the size of functional cardiac tissue, return of blood flow should be accomplished as soon as possible [2]. 


\subsection{Normoxic Mitochondria}

Mitochondria are highly abundant eukaryotic organelles that have been essential to the evolution of complex organisms and are the site of aerobic respiration. They are bound by two specialized membranes (Figure 1) that together create two mitochondrial compartments: intermembrane space (between the two membranes) and the internal matrix (within the inner membrane). The matrix is the site of the citric-acid cycle and the highly convoluted inner membrane is the site of oxidative phosphorylation and the locus of mitochondrial ATP-sensitive potassium channel (mitoK $\left.\mathrm{ATP}_{\text {AT }}\right)$. The outer membrane contains large numbers of integral proteins called porins, which form large aqueous channels through the lipid bilayer making it highly permeable to molecules of 5000 daltons or less. The inner membrane, on the other hand, is highly selective and largely impermeable to ions. Permeability to ADP, ATP, substrate anions and to $\mathrm{Na}^{+}, \mathrm{K}^{+}$and $\mathrm{Ca}^{2+}$ is mediated largely by specific channels and carriers. A tight protonelectrochemical gradient is maintained across this membrane in order to support the mechanism of ATP synthesis. The electron transport chain and ATP synthase are located within the inner membrane, which has a large surface area due to its cristae (or folds) in order to support these mechanisms.

Proper function of the heart requires a large amount of cellular energy and over $90 \%$ of cardiac metabolism is aerobic [3]. In order to maintain this 
metabolism, heart cells have a high oxidative capacity. It has been estimated that $25-35 \%$ of total cardiomyocyte volume is occupied by mitochondria [4]. About two-thirds of the ATP hydrolyzed by these mitochondria is utilized in the contractile apparatus of the heart, while the remaining is used in active transport in order to maintain ion balance, especially by sarcoplasmic reticulum $\mathrm{Ca}^{2+}$-ATPase and the sarcolemmal $\mathrm{Na}^{+} / \mathrm{K}^{+}$-ATPase [3]. In addition to being the site of the electron transport chain and the citric acid cycle, the mitochondria are responsible for mediating necrosis and apoptosis. 


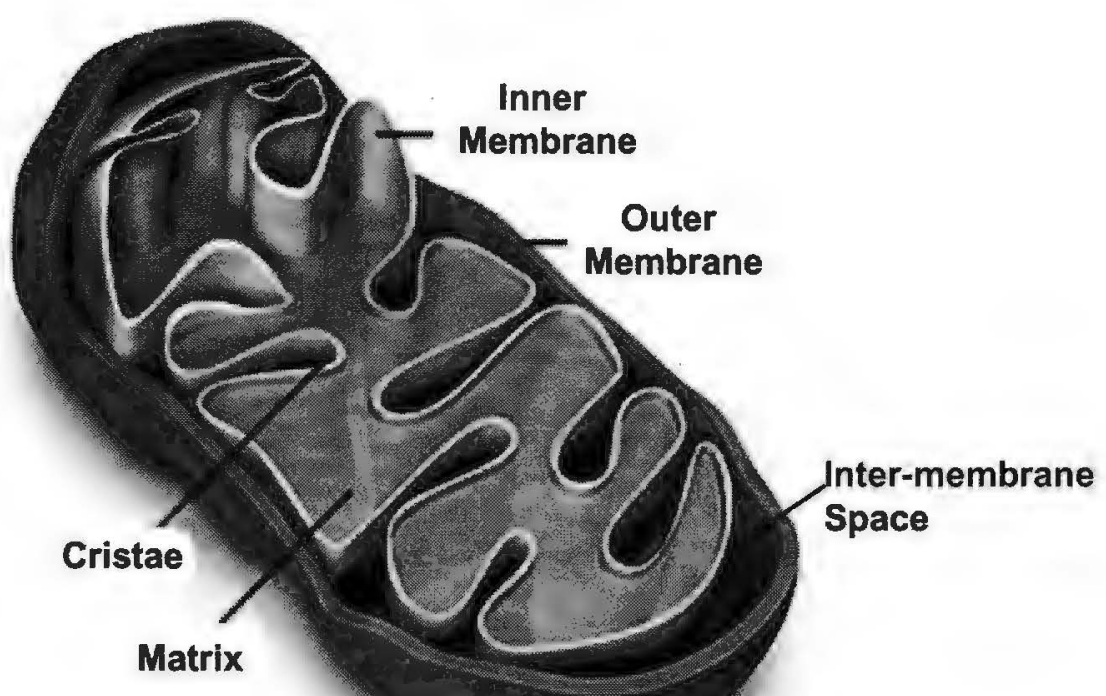

Figure 1. Internal structures of mitochondria (modified from http://www.cartage.org). 


\subsection{Ischemia-Reperfusion Injury}

During cardiac ischemia, blood flow to the heart decreases or stops completely, thus oxygen delivery to the mitochondria by and large ceases. The citric acid cycle is arrested and therefore no energy is available from oxidative phosphorylation. Non-esterified fatty acid levels rise leading to an accumulation of cytoplasmic $\mathrm{NADH}$ resulting in a severalfold rise in NADH/NAD ratio [3]. For several minutes after the arrest of oxidative phosphorylation levels of ATP may be maintained by glycolysis. Glycolysis, however, is unable to meet the demand of the beating heart for ATP for more than a few minutes [5]. In addition, after 30 minutes, lactate accumulates in the cell and cytospasmic $\mathrm{pH}$ decreases to 5.5-6 resulting in inhibition of glycolysis $[3,6]$. ADP levels increase rapidly, while ATP levels fall slowly to about $50 \%$ of [ATP] at normoxic conditions after 30 minutes of ischemia [7]. Sodium-hydrogen exchanger (NHE), although relatively quiescent under aerobic conditions, becomes activated by intracellular acidosis, causing the extrusion of $\mathrm{H}^{+}$and the influx of the concomitant $\mathrm{Na}^{+}$[8]. Due to low ATP levels the sarcolemmal $\mathrm{Na}^{+} / \mathrm{K}^{+}$-ATPase and sarcoplasmic reticulum $\mathrm{Ca}^{2+}$ ATPase become non-functional and cytoplasmic $\left[\mathrm{Na}^{+}\right]$and $\left[\mathrm{Ca}^{2+}\right]$ increase. $\mathrm{Na}^{+}$increase causes the $\mathrm{Na}^{+} / \mathrm{Ca}^{2+}$ exchanger to work in reverse, which inbibits $\mathrm{Ca}^{2+}$ efflux or even enhances the $\mathrm{Ca}^{2+}$ influx $[9,10]$. It has been reported that with prolonged ischemia NHE is inhibited by extracellular acidosis that eventually exceeds intracellular acidosis $[11,12]$. Soon, the 
mitochondrial electro-chemical gradient is almost entirely diminished resulting in a great depression of the mitochondrial membrane potential. When in this extreme state of stress mitochondria are likely to trigger necrosis (accidental cell death associated with membrane rupture) and apoptosis (programmed cell death).

Although it is essential to return blood flow to the heart in order to salvage the myocardium and preserve functionality of the organ, the process of reperfusion itself causes additional deleterious effects not observed during ischemia. This phenomenon is collectively referred to as ischemiareperfusion injury. When blood is reintroduced to an ischemic system, rapid washout of extracellular $\mathrm{H}^{+}$reactivates $\mathrm{NHE}$, resulting in further intracellular $\mathrm{Na}^{+}$accumulation. Again, $\mathrm{Ca}^{2+}$ influx follows causing abnormally high intracellular $\mathrm{Ca}^{2+}$ concentration. When oxygen is reintroduced to the respiratory chain, ubiquinone can become partially reduced to ubisemiquinone. This can in turn react with oxygen to produce superoxide that is reduced to hydrogen peroxide by superoxide dismutase [5]. Hydrogen peroxide, in the presence of ferrous ions, will form the highly reactive hydroxyl radical through the Fenton reaction $[5,13]$. These reactive oxygen species (ROS), which immediately increase slightly above normal when the heart becomes ischemic and then dramatically upon reperfusion [14] are extremely damaging to mitochondrial proteins. ROS have direct effects on complex 1 and complex 3 of the respiratory chain, as well as other iron sulphur proteins 
[5]. In addition, ROS may cause oxidation of glutathione that may then form mixed disulphides with proteins, which in turn inhibit protein pumps $[15,16]$. Overall, it is thought that the combined effects of ROS and $\mathrm{Ca}^{2+}$ overload are responsible for ischemia-reperfusion injury and determine whether the injury is reversible. In particular, mitochondrial injury by these agents may lead to the opening of mitochondrial permeability transition (MPT).

\subsection{Mitochondrial Permeability Transition}

The mitochondrial inner membrane barrier to diffusive ion fluxes is essential in order to maintain the chemiosmotic gradient necessary to drive ATP synthesis. During ischemia-reperfusion, several factors including matrix calcium overload, high oxidative stress, high phosphate and low ATP concentrations induce the opening of a non-selective pore in the inner mitochondrial membrane, referred to as mitochondrial permeability transition (MPT) or mitochondrial permeability transition pore. During reperfusion, when oxygen is introduced $\mathrm{ROS}$ are produced and, with $\mathrm{Ca}^{2+}$ overload that happens during ischemia, MPT opens. This step takes place within 1-2 minutes and this delay enables postconditioning. Once open, MPT allows unselective passage of any molecule up to $1.5 \mathrm{kDa}$ across the membrane. This uncouples oxidative phosphorylation, by allowing unrestricted proton movement across the membrane. The consequence of this is not only prevention of ATP synthesis but rapid consumption (hydrolysis) of ATP by 
reversing ATP synthase in a futile effort to re-establish the membrane potential [17]. Under these conditions the ionic and metabolic homeostasis of the mitochondria is disrupted and degradative enzymes such as phospholipases, proteases, and nucleases are activated. Irreversible damage will eventually occur and the cell will die via necrosis if MPT remains open $[3,5]$. A single opening of MPT is enough to depolarize the organelle as described and will activate further MPT opening within the same mitochondrion. This fully open state will result in a huge influx of small molecules, after which osmotically responsible water will follow resulting in matrix swelling. Swelling ultimately results in the rupture of the outer membrane (inner membrane withstands swelling due to the unfolding of cristae) and release of proapoptotic molecules in the intermembrane space such as cytochrome $c$ and apoptosis-inducing factor (AIF) $[18,19]$. Both cytochrome $c$ and AIF instigate apoptotic processes and lead to cell death $[17-21]$

\subsection{Ischemic Preconditioning}

Ischemic preconditioning (IPC) is an experimental physiological phenomenon in which brief episodes of ischemia and reperfusion protect the heart against subsequent lethal ischemic insult [22]. In the process of preconditioning, a series of cell signaling events modify cellular components in a manner that reduces myocardial damage from the sustained ischemia- 
reperfusion event. The IPC mechanism results in reduced infarct size, attenuating the incidence and severity of reperfusion-induced arrhythmias and preventing endothelial cell dysfunction [23]. Several endogenously released agents are involved in cardioprotection that results from preconditioning and include: opioids, norepinephrine, free radicals, adenosine, and bradykinin $[24,25]$.

\subsection{Modes of Protection}

In addition to ischemic preconditioning, several other modes of cardiac preconditioning have been described. (1) Calcium preconditioning (CPC) mimics IPC when calcium concentration increases briefly within the cardiomyocyte. Exogenous increase in calcium administered just prior to ischemia activates protein kinase $\mathrm{C}(\mathrm{PKC})$ and induces myocardial functional protection similar to IPC [26]. (2) Potassium channel openers (KCOs) result in cardiac preconditioning when administered prior to ischemia by increasing $\mathrm{K}^{+}$conductivity [27]. (3) Inhibition of sodium/proton exchanger by agents such as cariporide ultimately prevents $\mathrm{Ca}^{2+}$ overload and unusual $\mathrm{Na}^{+}$ gradients when administered prior to ischemia and thus causes decreased cardiomyocyte damage $[28,29]$. (4) Ischemic post-conditioning describes a phenomenon in which the heart undergoes ischemia and reperfusion with no pretreatment of any kind. Shortly after reperfusion, however, the heart is subjected to cycles of ischemia and reperfusion, resulting in similar extent of 
protection as IPC [30].

\subsection{Cardioprotection by Potassium Channel Openers}

Grover et al discovered that two drugs capable of cardioprotection, cromakalim and pinacidil, were KCOs [27]. Both were known vasodilators. The vasodilator activity of these agents was attributed to their ability to increase ATP-dependant $\mathrm{K}^{+}$channel $\left(\mathrm{K}_{\mathrm{ATP}}\right)$ conductance. In addition, there was electrophysiological evidence that indicated that both activated $\mathrm{K}_{\mathrm{ATP}}$ channels in cardiac myocytes [31]. Activation of $\mathrm{K}^{+}$channels in smooth muscle cells leads to hyperpolarization and consequent action potential shortening [32]. Cardioprotective effects of cromakalim and pinacidil was reversed by glyburide (glybenclamide) [27], which has been shown to be a high affinity blocker of ATP-dependent $\mathrm{K}+$ channels [33]. A variety of other KCOs were shown to be cardioprotective when administered prior to ischemia, including nicorandil, cromakalim, pinacidil, bimakalim, aprikalim, and P-1075 [27, 34-36]. These findings were consistent throughout different animal species [37-41]. Cardioprotective effects of all KCOs were reveresed by the blocker glyburide.

\subsection{MitoK $_{\text {ATP }}$ Mediates Cardioprotection by KCOs}

Initially, it was believed that the cardioprotection afforded by KCOs was modulated via the sarcolemmal ATP-sensitive $\mathrm{K}+$ channel ( sarcK $\left._{\text {ATP }}\right)$. 
Potassium activation in the cell leads to hyperpolarization of the cell and subsequent action potential shortening. Hyperpolarization due to increased potassium conductance may bring the resting potential further from the threshold that activates calcium channels; inhibiting calcium influx and reducing ischemia. This view was significantly questioned when several experiments showed that cardioprotection is possible without action potential duration (APD) shortening [42-44]. Also, in 1991, Inoue et al identified an ATP-sensitive potassium channel in the inner mitochondrial membrane in rat liver through patch clamp experiments, and Paucek reconstituted and partially purified ATP-sensitive potassium channel that was sensitive to glibenclamide ( $\mathrm{K}^{+}$channel closer) from rat liver and beef heart mitochondria $[45,46]$. A few years later, in 1996, work by Garlid et al put forth the hypothesis that it is the mitochondrial ATP-sensitive $\mathrm{K}+$ channel (mitoK $\mathrm{K}_{\mathrm{ATP}}$ ) that is responsible for the cardioprotective effects of KCOs and not sarcK $\mathrm{K}_{\text {ATP }}$ [47]. This finding was based on several independent observations and explained the paradoxical finding that the action potential shortening in cardiac myocytes and cardioprotection through KCOs did not correlate. First, it was demonstrated that various $\mathrm{KCOS}$ opened mitoK $\mathrm{ATP}_{\text {in }}$ is isolated mitochondria within their cardioprotective concentration range [47]. Second, sarcK $_{\text {ATP }}$ was shown to be almost completely insensitive to diazoxide, a pharmacological agent with known cardioprotective properties, or 5-HD (5-hydroxydecanoate), which blocks cardioprotection, while mitoK $\mathrm{ATP}_{\text {, }}$ 
assessed in isolated mitochondria, is sensitive to both in the pharmacological dose range [47-49].

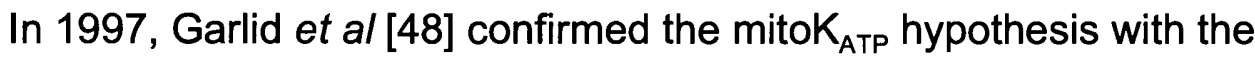
following findings: although both diazoxide and cromakalim (non-selective $\mathrm{KCO}$ ) afforded similar levels of protection against ischemia-reperfusion injury, cardioprotection via cromakalim was accompanied by some action potential duration (APD) shortening, whereas no APD shortening was caused by diazoxide, the selective mitoK $\mathrm{K}_{\text {ATP }}$ opener, demonstrating that diazoxide does not act via sarcK $\mathrm{ATP}_{\text {AT }}$ Since this discovery, numerous laboratories have provided evidence to support the paradigm that mitoK $\mathrm{ATP}_{\mathrm{AT}}$, and not the sarcK $_{\mathrm{ATP}}$, is the mediator of ischemic preconditioning and precondition by KCOs [50-55].

\subsection{MitoK $_{\text {ATP }}$ During Normal Conditions}

It is conceivable that mitoK $\mathrm{ATP}_{\mathrm{ATP}}$ evolved in order to provide a mode of cardioprotection, via IPC. However, this protein appears to exist in all mammalian species studied, including several that are not susceptible to ischemic heart disease [56]. Thus, it has been proposed that mitoK $\mathrm{ATP}_{\mathrm{AP}}$ plays a role in cardiac physiology during normal conditions and protection against ischemia happens to be a beneficial byproduct.

\section{9.a MitoK $_{\text {ATP }}$ in normal cell signaling}

There is some evidence that mitoK $_{\mathrm{ATP}}$ plays a role in normal cell 
signaling process that leads to cell growth. It has been shown that ouabain, a ligand of Na/K-ATPase, stimulates mitochondrial ROS production via a Rasdependent pathway [57]. Among others, this ROS production is an element that the ouabain and the cardioprotection pathways share in common, thereby linking the two [58]. Furthermore, it has been shown that the ouabain signaling pathway is blocked not only by ROS scavengers but also by 5-HD increasing support for the hypothesis that the two pathways are linked [58]. The interplays among these pathways in cardiomyocytes lead to changes in the expression of several genes. [56].

1.9.b MitoKATP opening in high work state - maintenance of positive ionotropy

During high work state, when the cardiomyocyte is undergoing high rates of ATP production and consumption, electron transport is high and the membrane potential significantly decreases. As Garlid explains in his review [56], this observation is identical to any other battery system, where drawing high currents ill decrease the output voltage. This decrease in membrane potential will result in the contraction of the mitochondrial matrix (because decrease in membrane potential decreases the influx of ions and the osmotically obligated water that enters with them), and the expansion of the inter-membrane space (IMS). However, mitoK $_{\text {ATP }}$, when open, provides a parallel potassium conductance that counteracts this matrix contraction, resulting in the preservation of matrix and IMS volume. IMS preservation is critical in maintaining the association of VDAC (voltage-dependent ion 
channel), which controls outer membrane permeability to ADP and ATP, and creatine kinase. Creatine kinase phosphorylates creatine, using ATP produced by the mitochondrial ATPase, creatine phosphocreatine and ADP. The high-energy phosphate bond of phosphocreatine has more energy than the bond of ATP, 10,300 calories per mole in comparison with 7,300 . Phosphocreatine presumably gets shuttled into the cytosol through VDAC and holds enough energy to reconstitute the high-energy bond of ATP. Therefore, this system provides an energy store in the cell and is incredibly important in the heart, where high work states are very frequent [56]. It has been proposed that endogenous signals open mitoK $\mathrm{ATP}_{\mathrm{P}}$ during high work state in order to maintain matrix volume and the association between VDAC and creatine kinase. Garlid and colleagues [56] tested the hypothesis that mitoK $_{\text {ATP }}$ opening is required for the positive inotropic response (increased

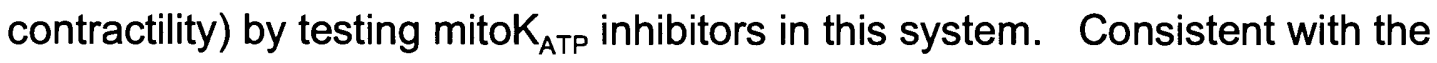
hypothesis, these authors found that mitoK ${ }_{\text {ATP }}$ blockers (5-HD and TPP ${ }^{+}$) prevented inotropic response indeed.

\subsection{MPT and mitoK $_{\text {ATP }}$}

Ischemic preconditioning as well as preconditioning by KCOs reduces MPT opening and decreases infarct size [59-61]. In order to describe the mechanism that acts in this situation, Korge et al [62] simulated ischemia in isolated mitochondria and caused MPT opening by exposing them to high 
$\mathrm{Ca}^{2+}$ and phosphate. Diazoxide (mitoK ${ }_{\text {ATP }}$ channel opener) and phorbol 12myristate 13-acetate (PMA, pharmacological agent that activates Protein Kinase $\mathrm{C}(\mathrm{PKC})$ by mimicking diacylglycerol - a physiological PKC activator) both blocked MPT opening and the release of cytochrome $c$, while 5-HD (mitoK $_{\text {ATP }}$ channel closer) reversed this effect [63]. These results supported the hypothesis that the protective mechanism of blocking MPT operates through PKC [49]. Working with genetically modified mice with cardiacspecific expression of recombinant $\mathrm{PKC} \varepsilon$, Baines et al [64] demonstrated that PKC $\varepsilon$ activity inhibited MPT opening in heart mitochondria. Other studies have demonstrated that inhibition of PKC by pharmacological agents blocks protection via IPC [65]. Also, hearts from PKC $\varepsilon$ knock-out mice do not exhibit protection by IPC [66]. In addition to PKC $\varepsilon$ involvement Kim et al [67] suggested that MPT inhibition operated through a guanylyl cyclasedependent signaling pathway by showing that cyclic GMP (cGMP) prevented MPT opening. Interestingly, it was shown that mitochondria swell in $\mathrm{K}^{+}$ medium after addition of Protein Kinase G (PKG) and cGMP [68]. This swelling is highly indicative of a potassium channel opening suggesting that PKG + cGMP cause mitoK ATP $_{\text {to }}$ open. In addition, KT5823, a specific inhibitor of PKG blocked this effect, while mitoK $_{\text {ATP }}$ specific opener, diazoxide, reversed inhibition by KT5823 [68]. In 2006 our laboratory demonstrated the mechanism by which mitoK $\mathrm{ATP}_{\text {AP }}$ opening inhibits MPT activation in heart, liver, and brain mitochondria. In agreement with previous experiments, this 
mechanism utilizes $\mathrm{PKG}$ and $\mathrm{PKC} \varepsilon$ as obligatory intermediates [49]. Upon activation in this process, mitoK $\mathrm{ATP}_{\mathrm{AT}}$ increases ROS. Interestingly, ROS (in this experiment $\mathrm{H}_{2} \mathrm{O}_{2}$ ), in concentrations at least 50 times smaller than those that induce MPT opening provides protection from MPT opening via PKC $\varepsilon$ independent of mitoK $\mathrm{ATP}_{\mathrm{AT}}$, suggesting that small amounts of ROS may be protective $[49,69]$. These data suggest that mitoK $_{\text {ATP }}$ opening protects the heart from ischemia-reperfusion by inhibiting MPT and thus cell death by apoptosis and necrosis (Figure 2). 


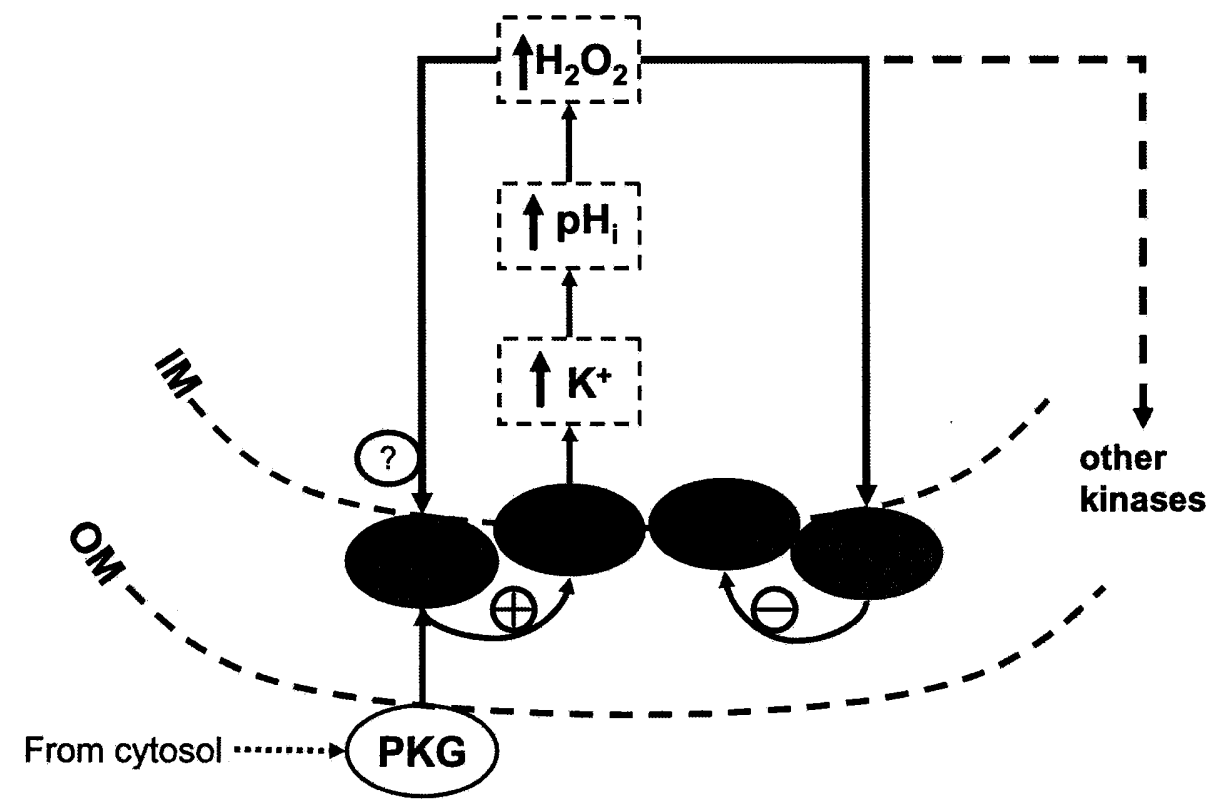

Figure 2. (Modified from [49])

The cardioprotective signaling pathway in mitochondria. Active PKG from the cytosol, which cannot cross the outer membrane of the mitochondria, phosporylates an unknown protein at the surface of the mitochondria. This protein presumably activates $\mathrm{PKC} \varepsilon 1$, that is thought to be bound to the outer surface of the inner mitochondrial membrane. Then, $\mathrm{PKC} \varepsilon 1$ phosphorylates and thus opens mitoK $_{\text {ATP }}$, resulting in an influx of potassium ions. Matrix potassium increase results in matrix alkalinization and eventually a small increase in matrix $\mathrm{H}_{2} \mathrm{O}_{2}$. This increase in $\mathrm{H}_{2} \mathrm{O}_{2}$ activates $\mathrm{PKC} \varepsilon 2$, causing the inhibition of MPT. PKC 11 and PKC 22 are identical enzymes localized in different pools within the pathway. It is also known that this modest increase in $\mathrm{H}_{2} \mathrm{O}_{2}$ activates a number of other kinases. 


\subsection{Mechanism of Cardioprotection Induced by MitoK $\mathrm{K}_{\text {ATP }}$}

The primary function of mitoK $\mathrm{K}_{\mathrm{ATP}}$ channels is to regulate mitochondrial volume $[70,71]$. It is absolutely essential to maintain appropriate mitochondrial matrix volume, and thus vesicular integrity, in the face of the ever changing environment of the inner membrane space, with numerous ions, molecules, and water leaving and entering the inner membrane space. This is largely accomplished by the regulation of $\mathrm{K}^{+}$transport, via diffusion and via mitoK $\mathrm{K}_{\text {ATP }}[70,71]$. Diffusive uptake of $\mathrm{K}^{+}$is exponential with voltage and is thus highly sensitive to the mitochondrial membrane potential. $\mathrm{K}^{+}$ uptake is followed by uptake of phosphate $(\mathrm{Pi})$ on the $\mathrm{Pi} / \mathrm{OH}^{-}$exchanger, followed by osmotically obligated water [72]. On the other hand, $\mathrm{K}^{+}$leaves the inner membrane space via the $\mathrm{K}^{+} / \mathrm{H}^{+}$antiporter, again, followed by water. In this way, the balance between the ion (and water) influx is balanced by the activity of $\mathrm{K}^{+} / \mathrm{H}^{+}$antiporter. During ischemia, the mitochondrial membrane potential is low, mitochondria depolarize due to anoxia and mitochondrial matrix contraction results. As a result, inner membrane space architecture gets highly distorted, and ATP hydrolysis is accelerated due to disruption of mitochondrial creatine kinase [71]. Increased $\mathrm{K}^{+}$conductance through the opening of mitoK $\mathrm{ATP}_{\text {AT }}$ may help to maintain inter-membrane space architecture and slow down the hydrolysis of ATP, allowing the use of creatine as substrate upon reperfusion [71]. 


\subsection{MitoK $_{\text {ATP }}$ in Other Tissues}

MitoK $_{\text {ATP }}$ has been shown to provide protection in pancreatic beta-cells by preventing the onset and development of diabetes in rats. The selective mitoK $_{\text {ATP }}$ opener, diazoxide, inhibited apoptosis by directly opening mitoK $K_{\text {ATP }}$ and this effect was completely abolished by 5-HD [73]. As in the heart, ischemia-reperfusion injury may also lead to apoptosis in the brain [74]. Mitochondria in the brain contain seven times more mitoK $\mathrm{ATP}_{\mathrm{AT}}$ channels then heart mitochondria [75]. There is support that mitoK ATP $_{\text {protects the brain }}$ against ischemia reperfusion injury in vivo models: diazoxide preserves neuronal-vascular function after cerebral ischemia in piglets [76] and induces protection induced by hypothermic circulatory arrest in canine models [77], both effects were reversed by 5-HD. A study in cultured cerebellar granule neurons, where $\mathrm{H}_{2} \mathrm{O}_{2}$ was used to simulate neuronal apoptosis, suggested that mitoK $\mathrm{ATP}_{\mathrm{AT}}$ provides neuroprotection by preserving mitochondrial inner membrane potential [78].

\subsection{The Argument}

Diazoxide and 5-HD have become synonymous with mitoK $\mathrm{ATP}_{\text {opening }}$ and closing, respectively. The paradigm that mitoK $\mathrm{ATP}_{\text {AT }}$ is the mediator of preconditioning via $\mathrm{KCO}$ sas been questioned by a number of investigators [79-83]. In particular, it has been proposed that diazoxide and 5-HD mediate cardioprotection independently of mitoK $\mathrm{ATP}_{\mathrm{A}}[79,81,83]$. This controversy has 
be intensified by the lack of a molecular identity for mitoK $\mathrm{K}_{\mathrm{ATP}}$. Throughout the last six years or so, several investigators, most recently Minners [79] have concluded that cardioprotection by diazoxide is afforded by respiratory chain inhibition $[81,82,84]$. In fact, it has been known for almost forty years that high doses of diazoxide significantly decrease mitochondrial respiration by inhibiting succinate-dehydrogenase $(\mathrm{SDH})[85]$. These investigators fail to take into account the differences in the concentrations of this drug in both circumstances. Diazoxide inhibits SDH at high concentrations, while cardioprotection is achieved in much lower doses. In fact, it is very reasonable to suppose that most hydrophobic drugs, such as DZX, when used in very high concentrations will embed themselves into the membrane and cause physiological changes. It is also important to point out that these arguments focus on diazoxide, ignoring the fact that many other mito $\mathrm{K}_{\text {ATP }}$ openers provide cardioprotection without inhibiting the respiratory chain.

The same three laboratories proposed that 5-HD, which is a hydroxy derivative of decanoate, antagonizes the effect of diazoxide by being metabolized like other medium-chain fatty acids in the heart. Again, metabolism of $5-\mathrm{HD}$ is already know from previous work [86]. 5-HD has a very short (7 minute) biological half life in dogs [86] and blocks cardioprotection when given 2 minutes, but not 8 minutes, before IPC [87]. These authors suggested that the short half life is due to $5-\mathrm{HD}$ being converted to 5-HD-CoA by mitochondria in the presence of ATP and CoA 
[56]. Those that have proposed this explanation for cardioprotection suggest that 5-HD blocks cardioprotection by interfering with normal cardiac metabolism, although do not explain how this may be. Again, these arguments do not explain why glibenclamide [48] and HMR1098 [88] block cardioprotection by diazoxide.

MitoK $_{\text {ATP }}$ openers diazoxide, 3-NPA, $\Psi \varepsilon R A C K$, and PKG will be utilized in our experiments. Therefore, they are briefly discussed in sections below.

\subsection{3-NPA}

3-Nitropropionate (3-NPA) is a widely distributed plant and fungal toxin first identified by Morris et al in 1954 as the primary toxic agent of Indigofera endecaphylla $[89,90]$. It is produced on moldy crops such as sugarcane and peanuts and causes severe neurological disorders in humans when consumed in sufficient amounts [91-93]. 3-NPA is said to be a suicide

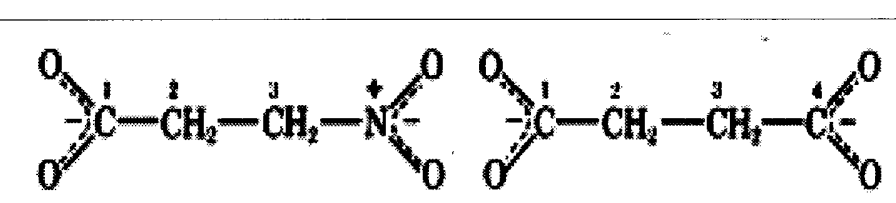

Figure 3. 3-NPA (left), in its carbanion form, is isoelectic with succinate (right).

$$
\begin{aligned}
& \text { inhibitor of succinate } \\
& \text { dehydrogenase (SDH), } \\
& \text { associated with the } \\
& \text { tricarboxylic acid cycle and }
\end{aligned}
$$

complex II in the respiratory chain. Alston et al demonstrated that the dianion form of 3-nitropropionate is the inhibitory form [90]. The carbanion form of this compound is isoelectric with succinate (Figure 3), SDH substrate [90], and reacts progressively with $\mathrm{N}-5$ of the covalently bound flavin to form a 
covalent adduct [94] (Figure 4). This binding is irreversible [90, 94]. Chemical preconditioning with 3-NPA has been shown to have a protective effect against ischemic hypoxic neuronal damage in vitro [95-97]. Interestingly, the symptoms of 3-NPA toxicity closely resemble those of Huntington's disease and thus provide a research model for understanding the mechanisms of Huntington's [98]. Several findings show that the type of neuronal death induced by 3-NPA is dose-dependent [99]. In vivo and in rat hippocampal cell cultures, intermediate doses of the compound result in apoptosis [100], while high doses led to NMDA-receptor dependent excitotoxic cell death. It is speculated that dependent on its concentration 3NPA can induce three different cellular responses: tolerance (preconditioning) [96], apoptosis, or necrosis. 3-NPA addition caused a pronounced decrease in [creatine phosphate/creatine] and a fall in [ATP/ADP] as well as [GTP/GDP] [98]. It has been well established that reductions in energy metabolism are neuroprotective. However, it is unlikely that preconditioning via low doses of 3-NPA is an example of this phenomenon because 3-NPA preconditioning is evident much later (several days) after normal ATP levels and SDH activity have been reestablished [96]. It may therefore be concluded that inhibition of SDH is not the mechanism by which 3-NPA is protective in the brain.

Riepe et al hypothesized that ATP-sensitive potassium channels may be responsible for the effect of administrating sub-lethal doses of 3-NPA after 
conducting electrophysiological studies on rat hippocampal slices [101]. Further investigation and in situ studies demonstrate that neuroprotection via 3-NPA was abolished by administration of glybenclamide and 5-HD [102]. Additionally, 3-NPA administration resulted in mitochondrial depolarization and these effects were also blocked by 5-HD [102]. These results suggest that mitoK $\mathrm{K}_{\text {ATP }}$ plays a significant role in 3-NPA preconditioning in the brain.

Several studies also suggest that 3-NPA protects the heart from ischemia-reperfusion injury. Experiments on a Langendorff apparatus demonstrated that 3-NPA provides significant cardioprotection [103]. Ockaili and coworkers demonstrated that 3-NPA induces an immediate and delayed cardioprotective effect in the heart as indicated by a significantly decreased infarct size compared with control animals. The mitoK $\mathrm{ATP}_{\text {AT }}$ selective opener, 5$H D$, abolished both the early and the delayed cardioprotective effects when administered before ischemia-reperfusion [104]. This evidence indicates that mitoK $_{\text {ATP }}$ is a mediator in heart preconditioning and cardioprotection via 3NPA. 


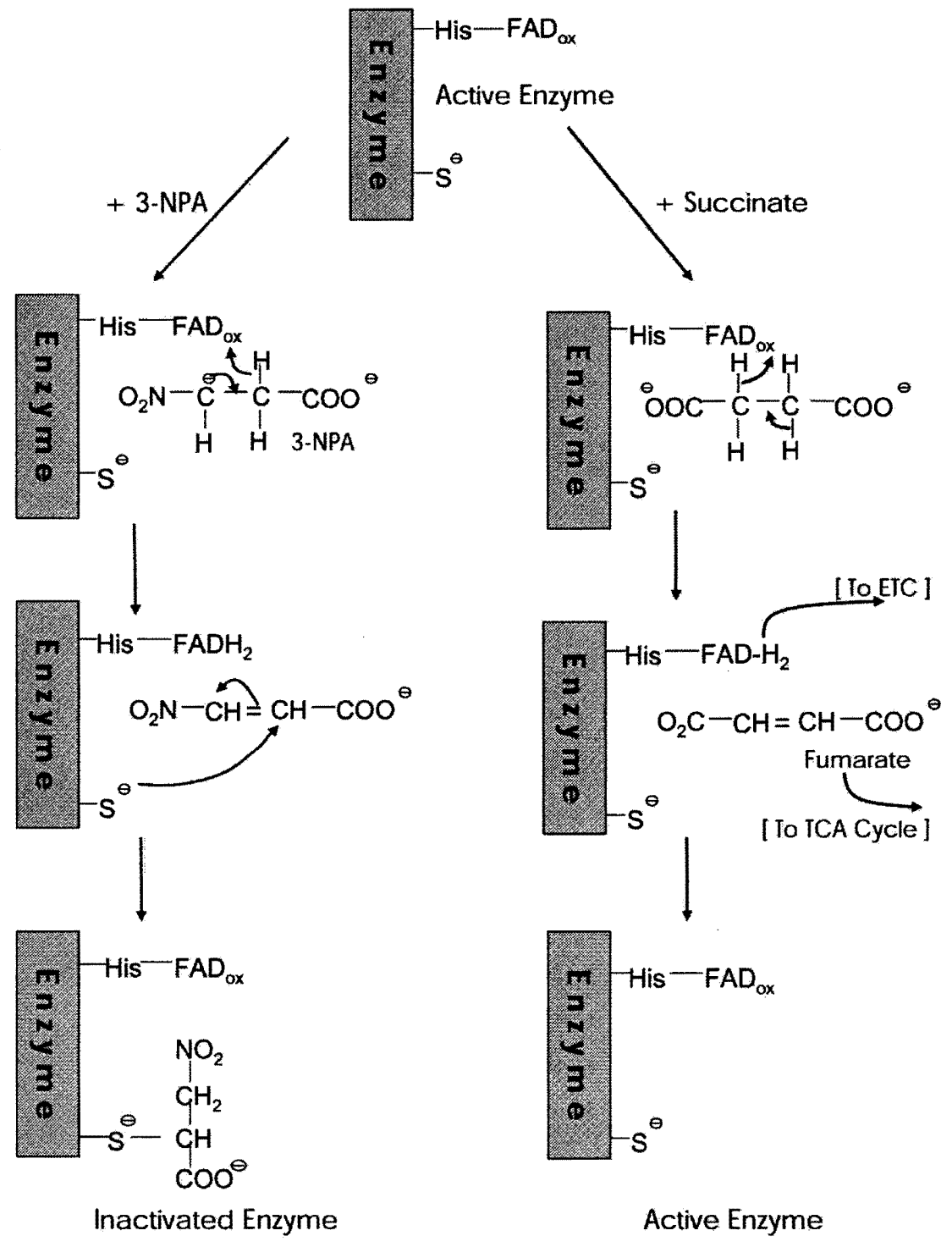

Figure 4. Proposed mechanism by which 3-NPA irreversibly deactivates succinate dehydrogenase (on the left) compared to the cyclic mechanism by which SDH converts succinate into fumarate and supplies electrons into the electron transport chain (ETC) (Modified from [94]. 


\subsection{Diazoxide}

Diazoxide (3-methyl-7-chloro-1,2,4-benzo- thiadiazin-1, 1 dioxide) (figure 5) is a synthetic drug that has been used as a diabetogenic agent, by

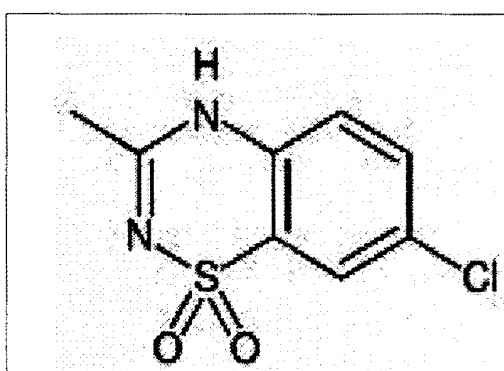

Figure 5. Molecular structure of diazoxide suppressing of insulin secretion in vivo and in vitro [85]. It is the most potent beta-cell $\mathrm{K}_{\mathrm{ATP}}$ channel opener known and it successfully hyperpolarizes the beta-cell, thereby inhibiting insulin secretion [105] and by preventing apoptosis in pancreatic beta-cells of pre-diabetic

and diabetic rats [73]. Diazoxide is also used inter-venously to treat severe hypertension as it relaxes arteriolar smooth muscle [106]. Both of these clinical applications of diazoxide were widely used before the discovery of ATP-sensitive potassium channels. In 1969, Schafer et al reported that diazoxide inhibited succinate dehydrogenase (SDH), complex II of the electron transport chain in isolated rat liver mitochondria and beef heart submitochondrial particles [85]. Their findings demonstrated that in high concentrations, diazoxide strongly inhibits succinate-supported respiration but not NADH-linked substrate oxidation. Belyaeva et al and Szewczyk et al reported that diazoxide (and other KCOs) also act on respiring mitochondria $[107,108]$. Their reports suggested that diazoxide effects on mitochondria are pharmacologically irrelevant because its effect was very weak at concentrations much higher than $\mathrm{K}_{1 / 2}$ values observed with sarcK $\mathrm{K}_{\text {ATP }}$ [109]. In 
1996 Garlid et al reported that diazoxide was a very potent activator of the ATP-sensitive potassium channel in intact mitochondria and proteoliposomes containing recontituted mitoK $_{\text {ATP }}$ [47]. No effect was observed on uninhibited potassium flux, likely explaining the low potencies that Szewczyk and Kelyaeva reported [47]. Due to the observation that diazoxide opens mitoKATP channel at a concentration that has no effect on the sarcK $\mathrm{K}_{\text {ATP }}$ channel, focus shifted from sarcK $\mathrm{K}_{\text {ATP }}$ to mitoK $\mathrm{K}_{\text {ATP }}$ channel as mediator of cardioprotection [47].

\subsection{TERACK}

$\Psi_{\varepsilon R A C K}$ is a selective PKC\& (Protein Kinase C epsilon) activator peptide. It is derived from PKC $\varepsilon$ and is eight amino acids long [HDAPIGYD]. PKC $\left(\mathrm{Ca}^{2+}\right.$-dependent protein kinase $)$ is a serine/threonine kinase found abundantly in many different cell types. PKC $\varepsilon$ is one PKC isozyme (one of six) that is constitutively present in heart mitochondria [110]. There are many reports that $\mathrm{PKC} \varepsilon$ activation plays a critical role in transmitting a signal that induces cardioprotection [68, 111-114]. Baines et al [64] and Korge et al [63] have shown that PKC activation is able to inhibit MPT opening. Costa et al [49] demonstrated that $\Psi \varepsilon R A C K$ provides cardioprotection through mitoK $K_{\text {ATP }}$ through the inhibition of MPT. This finding that $\Psi \varepsilon R A C K$ provides cardioprotection by mimicking ischemic preconditioning has been demonstrated by a number of laboratories $[111,113,115,116]$. 


\subsection{PKG}

cGMP-dependent protein kinase (PKG) is an abundant serine/threonine kinase activated by cyclic GMP (cGMP), in fact, it is the major intracellular receptor of cGMP [117]. It is present in high amounts in platelets, cerebellum, smooth muscle, cardiac muscle, hippocampus, dorsal root ganglia, neuromuscular end plate, and the kidney vasculature. Low levels have been detected in granulocytes, vascular endothelium, chondrocytes, and osteoclasts. PKG phosphorylates a number of physiologically relevant proteins involved in regulating the contractile activity of smooth muscle cells, regulation of cell differentiation and proliferation, inhibition of platelet aggregation and apoptosis [118, 119]. Han et al [120] first suggested that $P K G$ is involved in the signaling pathway that induces cardioprotection via ischemic preconditioning in rabbit ventricular myocytes. In their experiments, PKG was found to be responsible (at least in part) to phosphorylation and activation of $\mathrm{K}_{\text {ATP }}$ channels. Selective PKG inhibitors abrogated any effects [120]. Oldenburg et al [121] studied mitochondrial ROS generation by bradykinin and concluded that PKG activation (in their case by ROS) triggers preconditioning by opening mitoK $\mathrm{ATP}_{\text {. }}$ In order to uncover the mechanism by which PKG acts on mitoK ${ }_{\text {ATP }}$, Costa et al [68] conducted light scattering experiments which demonstrated that active PKG (and CGMP necessary to activate it) is indeed necessary to open mitoK $\mathrm{K}_{\text {ATP }}$ in vitro, and KT5823, a specific PKG inhibitor, blocked this effect. Interestingly, the inhibition of PKG by KT5823 was reversed by the addition of the specific 
mitoK $_{\text {ATP }}$ opener diazoxide [68]. In addition, PKG-induced effect was reversed by $5-\mathrm{HD}$ (selective mitoK $_{\text {ATP }}$ inhibitor) [68]. These investigations suggest that active PKG activates mitoK $\mathrm{KTP}_{\text {fP }}$ by indirect phosphorylation, and that this phenomenon is not limited to cardiomyocytes and has been observed in brain and liver mitochondria [68].

\subsection{Overall Hypothesis}

Several investigators have suggested that cardioprotection afforded by ischemic preconditioning is not mediated through mitoK $\mathrm{ATP}_{\text {DP }}$ but results from the inhibition of Complex II of the electron transport chain, succinate dehydrogenase. In this study, I have examined four chemically distinct and unrelated pharmacological agents, all of which have been shown to open mitoK $_{\mathrm{ATP}}$, to demonstrate that the said cardioprotective effect mediated by mitoK $_{\text {ATP }}$ is entirely independent of SDH. 


\section{Methods}

\subsection{Animals}

Male rats of the Sprague-Dawley variety were used in all experiments. The rats were about 2 months old and weighed $225-249 \mathrm{~g}$. They were housed two per cage in a $24^{\circ} \mathrm{C}$ room and were fed and watered ad libitum. Diet consisted of standard rodent formula chow from LabDiet. All procedures involving animals are in accordance with the American Physiological Society "Guiding Principles in the Care and Use of Animals" and was approved by Institutional Animal Care and Use Committee at Portland State University.

\subsection{Mitochondrial Isolation}

One or two rats were anesthetized with $\mathrm{CO}_{2}$ for $20-30$ seconds and immediately decapitated. An incision into the chest cavity was made using surgical scissors and hearts were quickly removed and rinsed in ice-cold Buffer A (250mM sucrose, 10mM HEPES pH 7.2, 5mM K-EGTA, and $1 \mathrm{mg} / \mathrm{mL}$ fatty-acid free BSA). Hearts were squeezed manually until most of the blood was removed. The hearts were then finely minced in Buffer A containing $1 \mathrm{mg} / \mathrm{mL}$ protease (Nagarse) for approximately 40 seconds. The suspension was then diluted with Buffer $A$ and homogenized with a motorized Teflon pestle until the homogenate looked uniform (about 45 seconds). The entire homogenate was then divided equally into two $30 \mathrm{~mL}$ plastic tubes and 
diluted with additional Buffer $A$ to bring the volume just shy of the top of the tubes. These were then spun at $1700 \mathrm{~g}$ for 3 minutes. The resulting supernatant containing the mitochondria was decanted into clean, ice-cold tubes and further centrifuged at $9000 \mathrm{~g}$ for 5 minutes. Pellet from the first spin containing blood cells and cellular fractions was discarded. The pellet from the second spin was carefully resuspended in Buffer B (Buffer A minus BSA) and centrifuged again for 4 minutes at $2300 \mathrm{~g}$. The resulting supernatant was centrifuged one more time to pellet the isolated mitochondria at $9000 \mathrm{~g}$ for 5 minutes. This final mitochondrial pellet was resuspended in about $200 \mu \mathrm{L}$ of Buffer B and stored on ice.

\subsection{Protein Measurement}

All protein was measured in Thermo Spectronic Genesys 20 using the Biuret Method first described by Gornall [122].

\subsection{Measurement of Mitochondrial Volume}

Mitochondrial matrix volume was measured by light scattering technique as first described by Beavis [123]. Mitochondria respond to osmotic pressure of their environment by taking up, or pumping out of water. When osmolarity outside the mitochondria increases and salt begins to enter the mitochondrial membrane - obligated water follows resulting in mitochondrial matrix swelling; shrinking occurs due the reverse. When mitoK $_{\text {ATP }}$ is opened, regardless of the cause, potassium ions and water flow 
into the matrix and swelling is observed. Matrix contraction is observed when mitoK $_{\text {ATP }}$ is closed. Therefore, mitochondrial swelling and shrinking in a potassium rich medium is indicative of the state of mitoK $\mathrm{K}_{\text {ATP. }}$. The light scattering technique utilizes a Brinkmann PC 700 colorimeter light probe fitted with a $520 \mathrm{~nm}$ filter. A small mirror about $1 \mathrm{~cm}$ below the light source reflects the light that has not been absorbed back into the system. Increase in matrix volume is accompanied by a decrease in the intensity of light scattered by the suspension, because as mitochondria swell, they absorb more (and therefore scatter less) light $[123,124]$. The probe is normally immersed in $2 \mathrm{~mL}$ of assay medium and mitochondria protein $(0.1 \mathrm{mg} / \mathrm{mL})$ suspension, which is constantly stirred and maintained at $30^{\circ} \mathrm{C}$. Absorbance is measured and quantified [123] using a computer program developed in our laboratory. It is based on the principle that reciprocal absorbance $(A)$ of the mitochondrial suspension (proportional to matrix volume, which depends on: medium osmolality, matrix solute content, and the concentration of mitochondria [123], when corrected for the extrapolated absorbance at infinite protein concentration is linearly related to the matrix volume. This absorbance is then converted to beta $(\bullet)$, which corrects for variations in protein concentraion:

$$
\beta \equiv \frac{P}{P S}\left(A^{-1}-\alpha\right)
$$

where $\cdot$ is the machine constant $(0.25$ in the case of our apparatus), A is 
absorbance, $P$ is mitochondrial concentration $(\mathrm{mg} / \mathrm{mL})$, and Ps (equals $1 \mathrm{mg} / \mathrm{mL}$ ) is introduced to make $\cdot$ a scaled dimensionless quantity [123]. Conversion to $\cdot$ allows comparison of multiple experiments. The light scattering assay medium contains $120 \mathrm{mM} \mathrm{KCl}, 10 \mathrm{mM}$ HEPES $(\mathrm{pH} 7.2)$, $0.1 \mathrm{mM}$ EGTA, $10 \mathrm{mM}$ succinate, and $5 \mathrm{mM}$ phosphate. Rotenone $(5 \mu \mathrm{M})$, which inhibits complex I of the electron transport chain and the reverse electron transfer from complex II to complex I as well as oligomycin $(0.67 \mu \mathrm{M})$, which inhibits ATP synthesis by the ATPase and consequent decrease in membrane potential are also added to all assay media.

MitoK $_{\text {ATP }}$ openers and closers were added to the assay media in appropriate concentrations to determine their effect on mitoK $\mathrm{K}_{\text {ATP }}$ (swelling indicates open channel, shrinkage - closed).

\subsection{Measurement of Mitochondrial Respiration}

Respiration was measured using a Yellow Springs Instruments oxygen electrode (Clark polarographic sensor), model 53. Electrode is connected to a chamber containing $2 \mathrm{~mL}$ of respiration solution of constant temperature $\left(25^{\circ} \mathrm{C}\right)$. At normal conditions this chamber contains a set amount of oxygen (960ng atoms $\mathrm{O}$ in $2 \mathrm{~mL}$ at $25^{\circ} \mathrm{C}$ ). After the addition of respiring mitochondria, the oxygen amount decreases and this linear rate is plotted on the computer that is connected to the electrode. Chemicals were added to the assay chamber containing the assay medium and mitochondria and their effect on respiration were observed. Respiration assay medium contains: $110 \mathrm{mM}$ 
sucrose, $10 \mathrm{mM}$ HEPES pH 7.2, 2.5mM Pi, 0.1mM EGTA, 0.5mM MgCl2, and $10 \mathrm{mM}$ succinate. $5 \mu \mathrm{M}$ rotenone was also added to each run in order to inhibit Complex I of the electron transport chain.

\subsection{Solutions}

All solutions were made with deionized water from Millipore Synergy 185. For contents of each medium please refer to sections above.

\subsection{Chemicals and Reagents}

Most chemicals were purchased from Sigma Chemical Co. except for PKG (Promega), cGMP (EZ Biolabs), and IERACK (EZ Biolabs).

\subsection{Data Analysis}

All data analysis was done using the program ORIGIN by Microcal. Respiration data were analyzed as follows. Each dose was assessed in an independent run. Mitochondria and rotenone were added immediately (at time 0), 100 seconds later CCCP (carbonyl cyanide m-chloro phenyl hydrazone, a mitochondrial uncoupling agent) $(35 \mu \mathrm{M})$ was added, 100 seconds after that the appropriate drug was added. The CCCP alone and $\mathrm{CCCP}+$ drug rates were converted into $(\mathrm{ng} \text { atoms oxygen })^{\star}\left(\mathrm{min}^{-1}\right)^{\star}(\mathrm{mg}$ protein

$\left.{ }^{1}\right)$. Then a ratio of $(C C C P+$ drug $)$ rate/(CCCP) rate was calculated and multiplied by $100 \%$ in order to calculate "\% of control". Thus, each individual 
run had its own no drug control to account for slight differences in pipetting, stirring, mitochondrial viability, and so on in different runs. 


\section{Results}

\subsection{Diazoxide}

Diazoxide opens mitoKATP at $30 \mu \mathrm{M}$ in rat heart mitochondria. Figure 6 demonstrates the swelling that is associated with mito $\mathrm{K}_{\text {ATP }}$ opening due to the presence of diazoxide. This opening is reversed by 5-HD. Diazoxide concentrations above $1 \mathrm{mM}$ inhibit succinate-supported respiration by $75 \%$ in rat heart mitochondria, $\mathrm{IC} 50=140 \mu \mathrm{M}$ (Figure 7).

\subsection{3-NPA}

3-NPA opens mitoKATP at 10nM in rat heart mitochondria (Figure 8). This opening was reversed by 5-HD. 3-NPA inhibits succinate supported respiration, IC50 $1.05 \mathrm{mM}$.

\subsection{PKG}

PKG + cGMP do not inhibit succinate-supported respiration below $96 \%$ of full function in the dose range tested. Figure $10 \mathrm{~b}$ demonstrates the raw respiration data for these experiments, while figure 10 a shows the doseresponse. 


\subsection{TERACK}

I\&RACK does not inhibit succinate-supported respiration below $92 \%$ of full function in the presence of rotenone within the tested dose (Figures $11 a-b)$. 


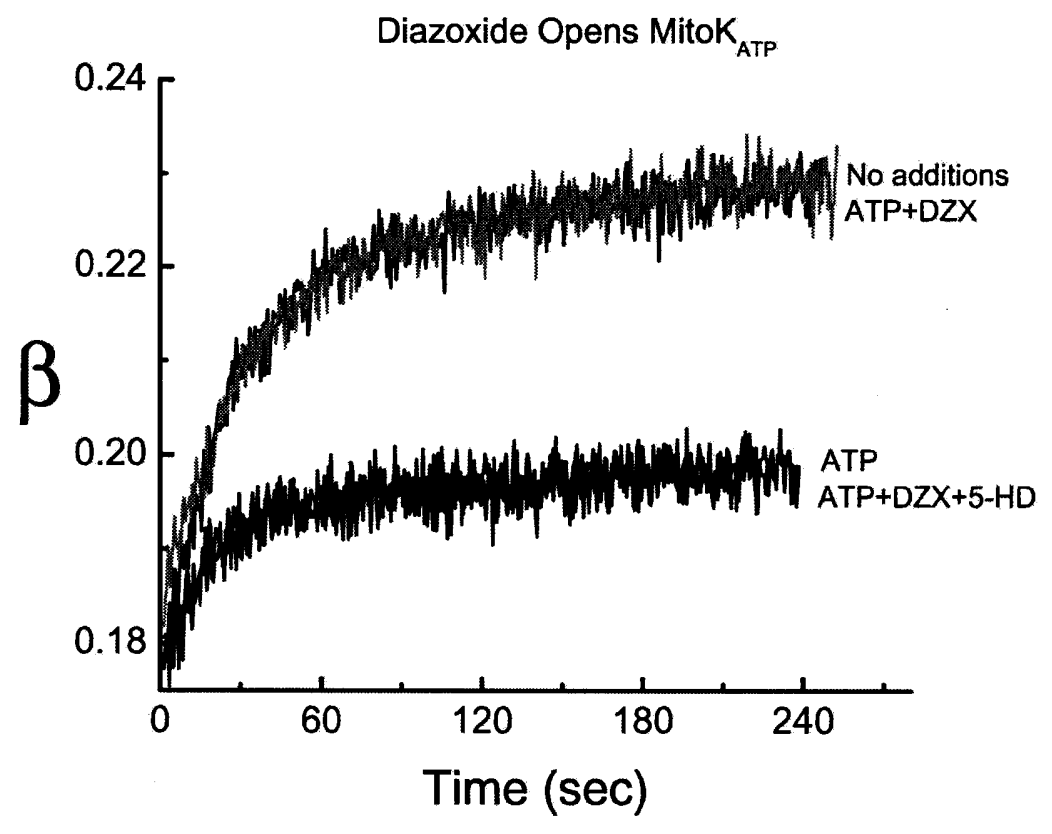

Figure 6. Light scattering assay results demonstrating that diazoxide $(30 \mu \mathrm{M})$ opens mitoK $\mathrm{ATP}_{\text {in }} \mathrm{KCl}$ medium. 5-HD reverses this opening in the presence of ATP $(n=4)$. 


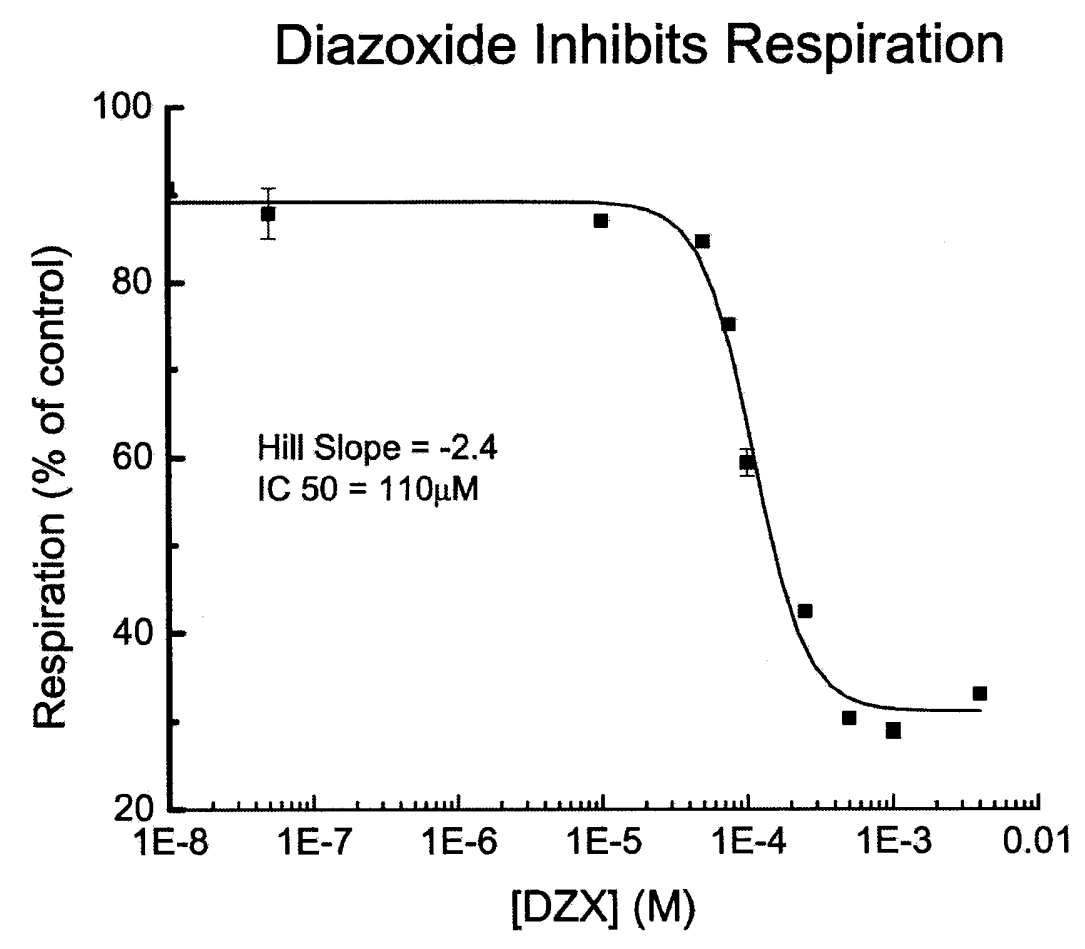

Figure 7. Respiration assay results demonstrating that diazoxide inhibits succinate-supported respiration. Hill slope $=-2.4$, IC $50=110 \mu \mathrm{M}$, sucrose medium, in the presence of rotenone $(n=3)$. 


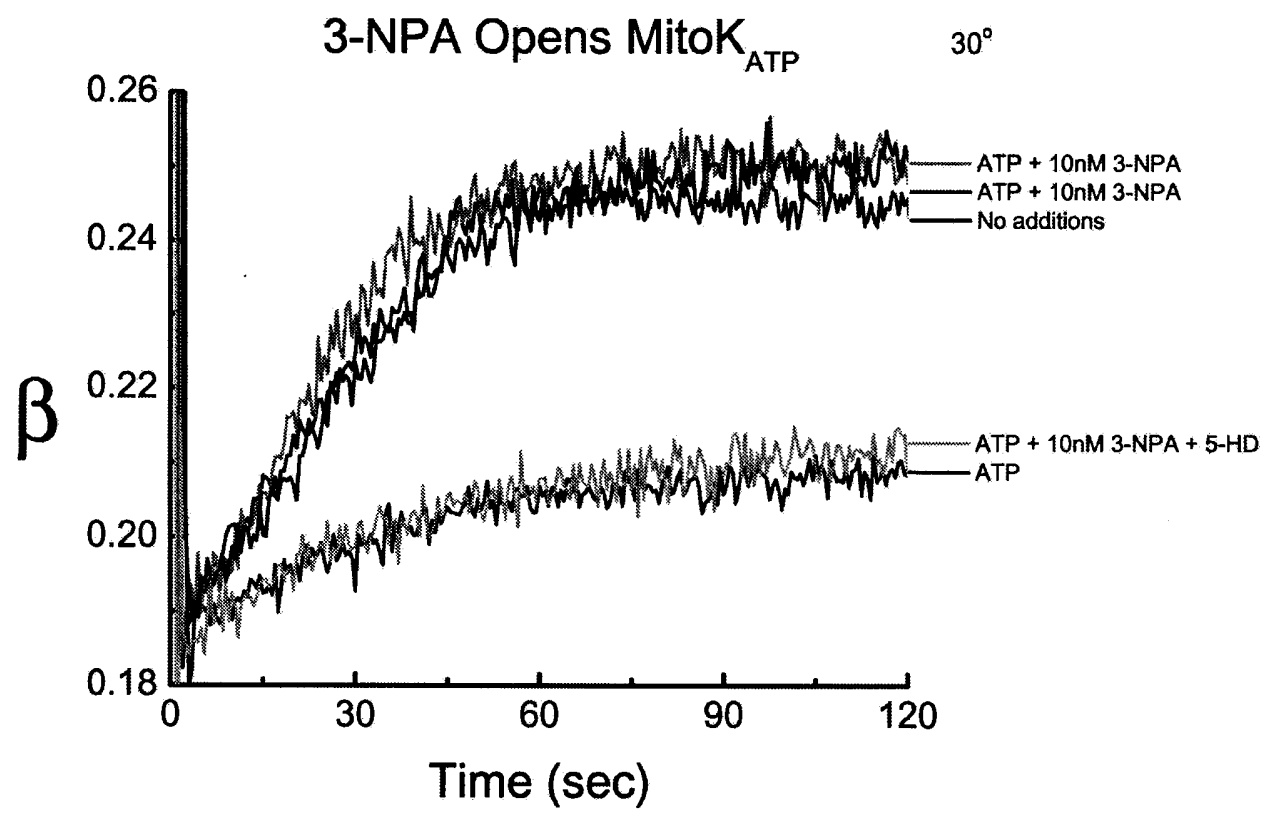

Figure 8. Light scattering assay demonstrating that 3-NPA (10nM) opens mitoK $_{\mathrm{ATP}}$ in isotonic $\mathrm{KCl}$ medium, in the presence of succinate, rotenone, and oligomycin. This effect is reversed by $5-H D(n=1)$. 
3NPA Inhibits SDH

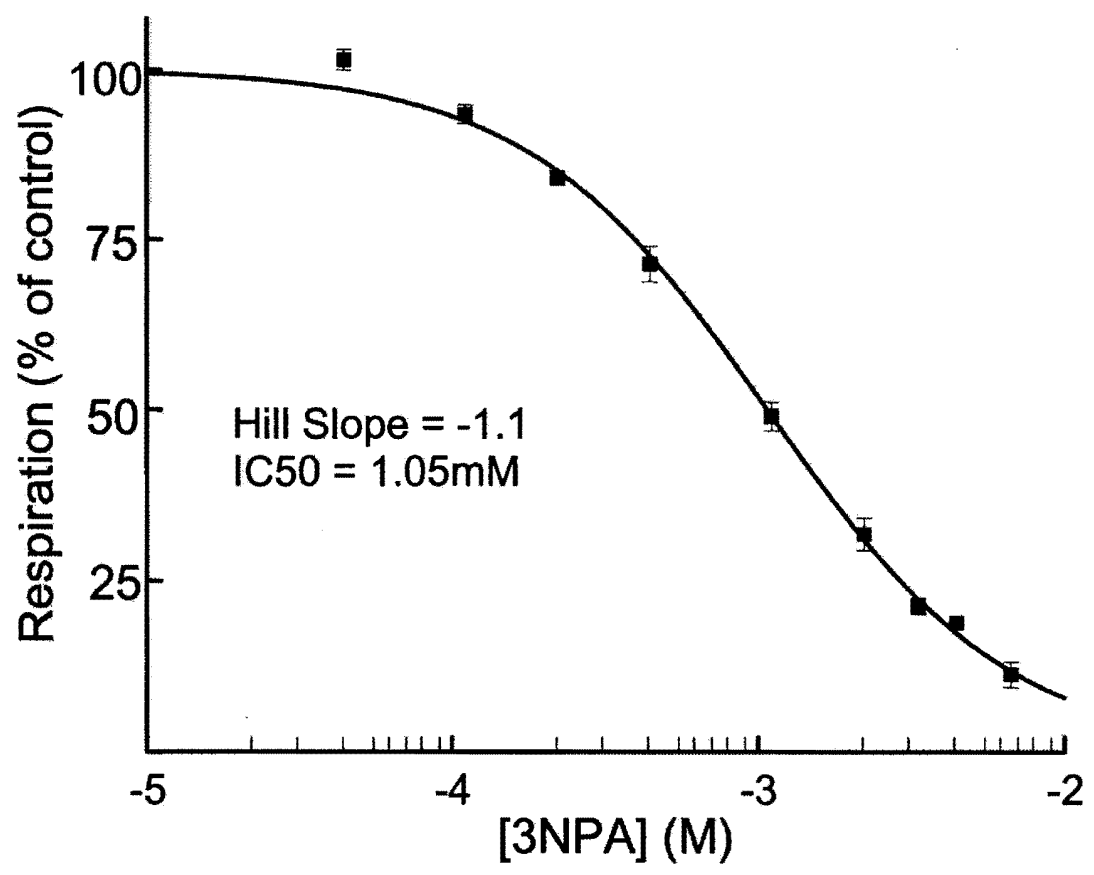

Figure 9. Respiration assay demonstrating that 3-NPA inhibits succinatesupported respiration in sucrose medium, in the presence of rotenone. Hill Slope $=-1.1$, IC $50=1.05 \mathrm{mM}(n=4)$. 
PKG does not Inhibit Respiration

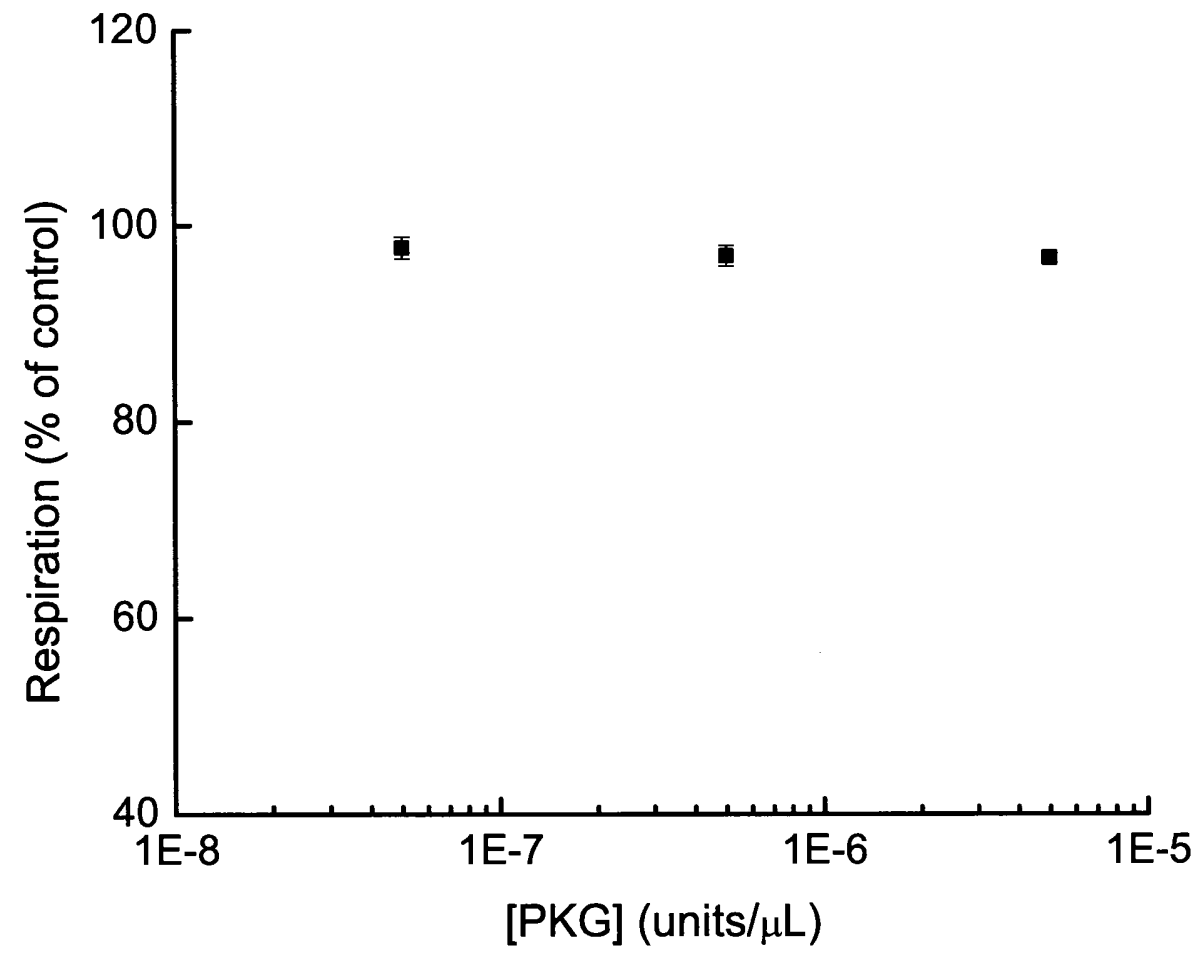

Figure 10a. Respiration assay demonstrating that PKG + cGMP do not inhibit succinate-supported respiration in sucrose medium, in the presence of rotenone $(n=3)$. 


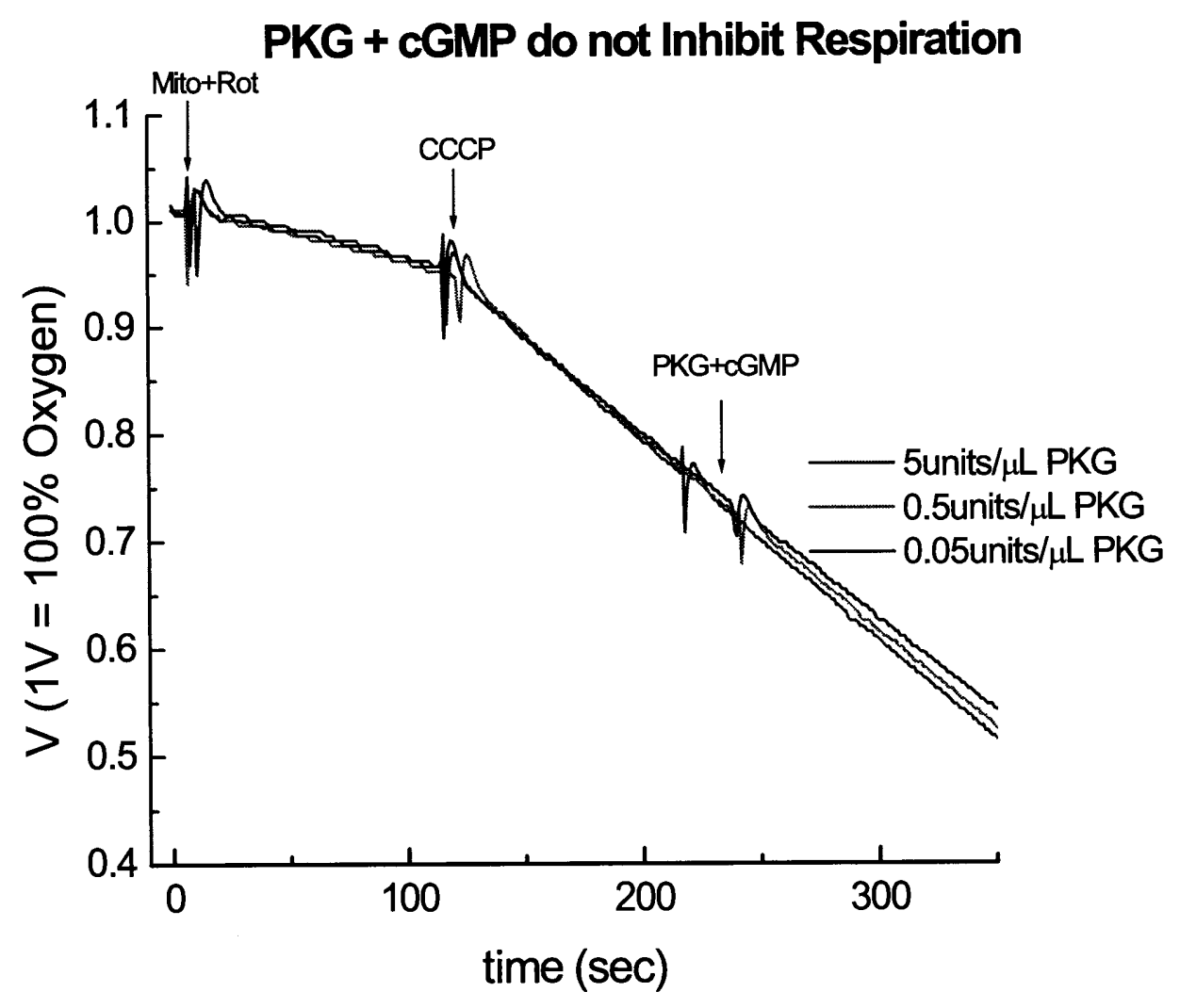

Figure 10b. Raw traces from respiration assay demonstrating that PKG + cGMP do not inhibit succinate-supported respiration in sucrose medium, in the presence of rotenone $(n=3)$. ( 1 unit = amount of kinase required to incorporate $1 \mathrm{pmol}$ of phosphate into the test heptapeptide (RKRSRAE) per minute, at $30^{\circ} \mathrm{C}$ ) 


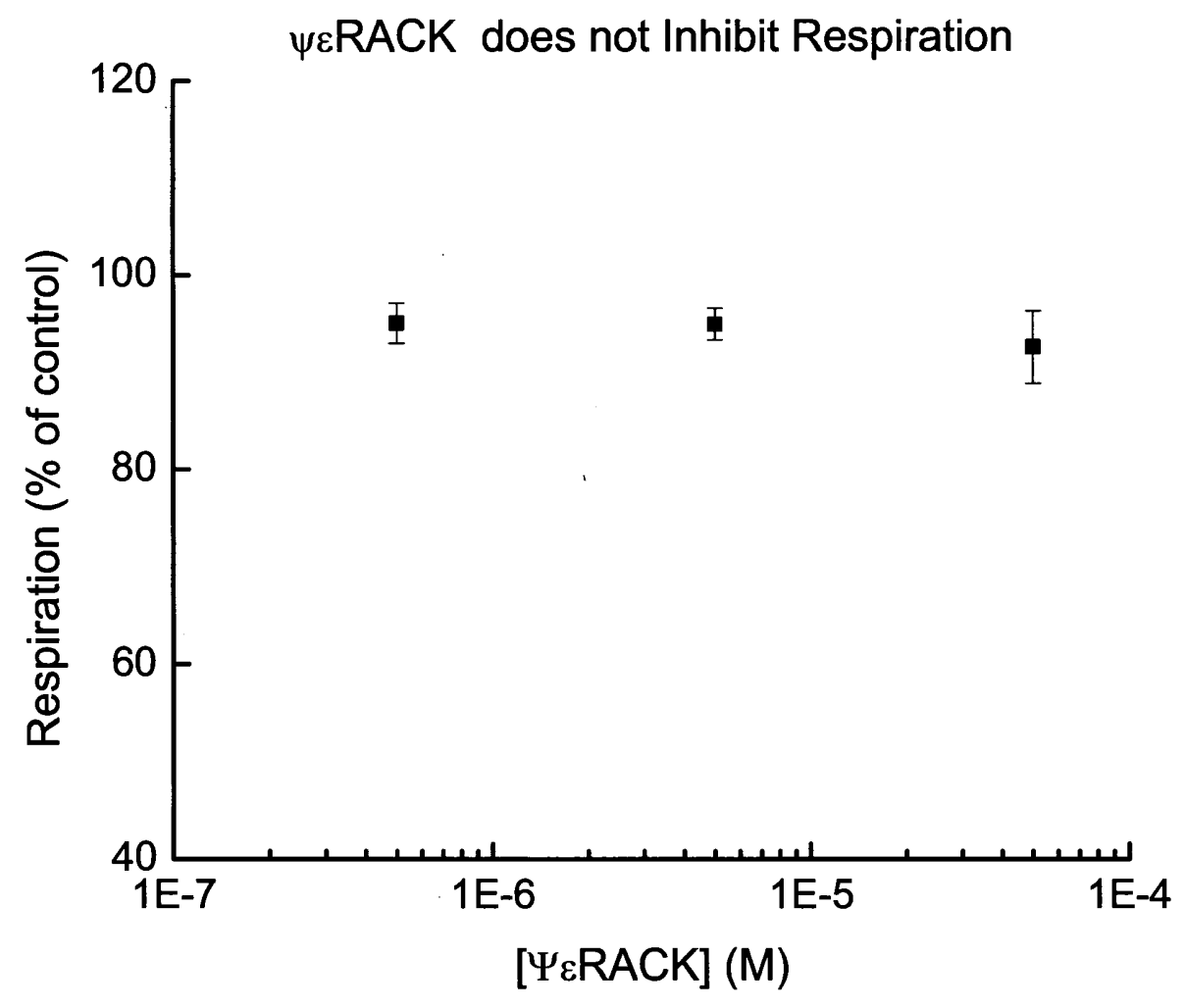

Figure 11a. Respiration assay showing that $\Psi \varepsilon R A C K$ does not inhibit succinate-supported respiration in the tested range. Sucrose medium, in the presence of rotenone $(n=3)$. 


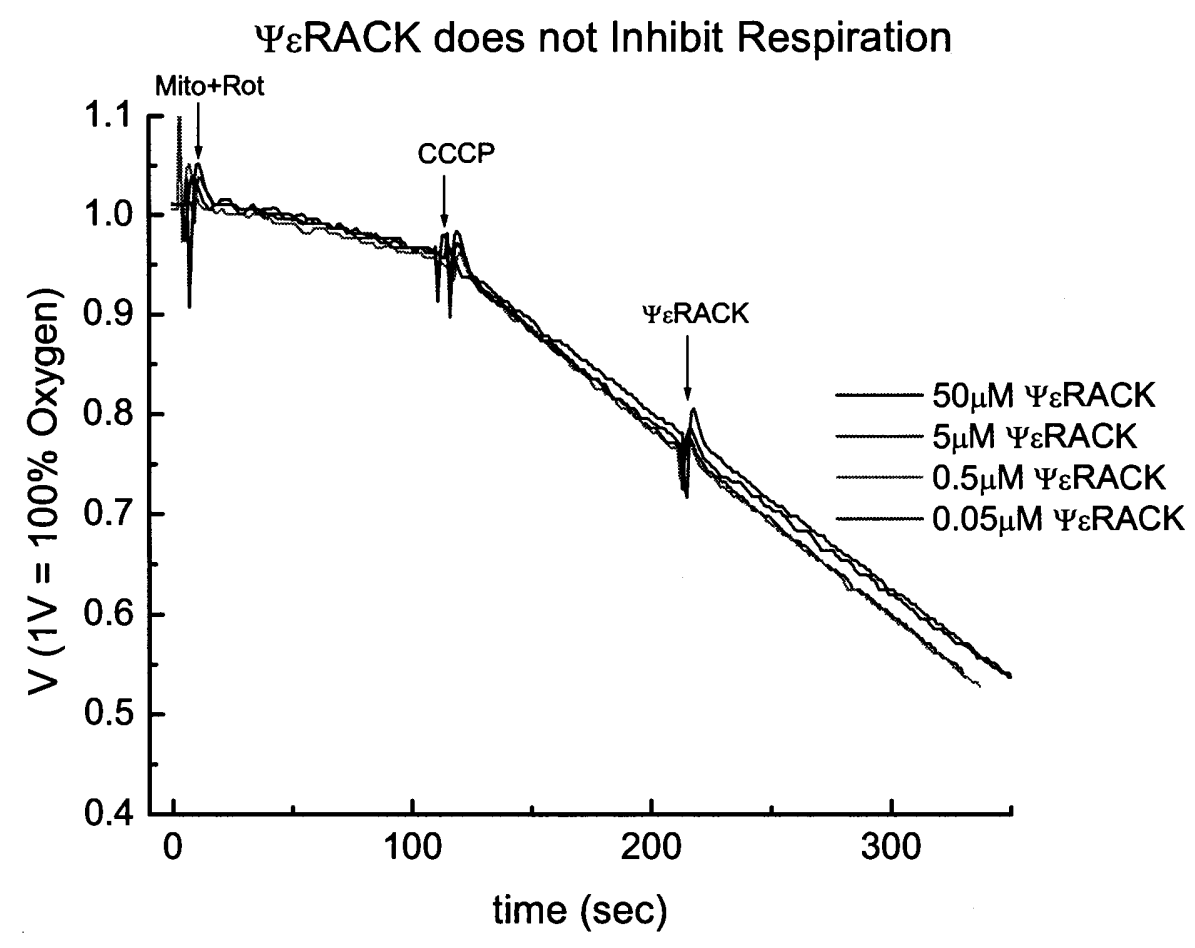

Figure 11b. Raw traces from respiration assay demonstrating that $\Psi \varepsilon R A C K$ does not inhibit succinate -respiration in the tested range. Sucrose medium, in the presence of rotenone $(n=3)$. 


\section{Discussion}

In 1986, Murry et al. described a paradoxical phenomenon whereby brief ischemic insults reduce damage to the heart caused by a subsequent, prolonged ischemic event [22]. Since 1989, when Grover et al. suggested that opening $\mathrm{K}_{\mathrm{ATP}}$ channels protects the heart from ischemia-reperfusion injury, there has been a growing interest in investigating the details of this mechanism. Although the classical sarcolemal $\mathrm{K}_{\mathrm{ATP}}$ channel was though to be the mediator of this cardioprotective pathway [125-127], compounding evidence suggested that the mitochondrial $\mathrm{K}_{\text {ATP }}$ channel, located in the inner mitochondrial membrane, was responsible for this effect $[45,47,54,55]$.

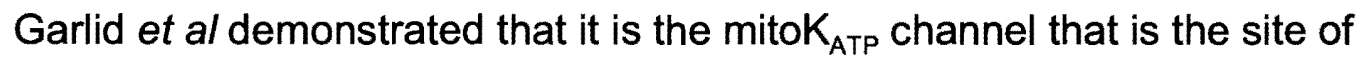
action of all $\mathrm{K}_{\mathrm{ATP}}$ channel openers [48]. This shift of paradigm has stirred a lot of debate as the details of this cardioprotective mechanism are investigated.

Some of the difficultly in pinpointing the mechanism by which mitoK $\mathrm{ATP}_{\text {ATP }}$ induces cardioprotection lies in the fact that molecular identity of this channel remains unclear. Indeed, what is known about mitoK $\mathrm{ATT}_{\text {comes largely from }}$ pharmacological investigation. SarcK ${ }_{\text {ATP }}$ channels have been molecularly defined as an octamer composed of four pore-forming inwardly-rectifying potassium $\left(\mathrm{K}_{\mathrm{ir}} 6.1\right.$ and $\left.\mathrm{K}_{\mathrm{ir}} 6.2\right)$ subunits and four sulfonylurea receptors (SUR2A), which confer a regulatory role and a sensitivty of the channel to ATP and pharmacological regulators [128]. MitoK $\mathrm{ATP}_{\mathrm{P}}$ channels share some 
pharmacological, and thus likely structural, properties with the classical sarcK $_{\text {ATP }}$ counterpart. Both channels are activated by pinacidil and inhibited by glibenclamide $[46,48]$. In order to study the mechanism of cardioprotection, which has been suggested to operate through mito $\mathrm{K}_{\mathrm{ATP}}$, it is crucial to utilize specific activators and inhibitors of this channel. Obviously, it is also important to ensure that the specific pharmacological agents don't have effects on other, relevant systems.

Diazoxide and 5-hydroxydecanoate have been utilized as a selective mitoK $_{\text {ATP }}$ channel opener and closer, respectively. Several investigators, most recently Minners et al [79], have rejected the role of mitoK $\mathrm{ATP}_{\text {in }}$ cardioprotection on the basis that diazoxide (and 5-HD) effects that have been attributed to mitoK $\mathrm{ATP}_{\mathrm{AT}}$ are actually due to these drugs' effects on mitochondrial respiration. Therefore, it was a goal of this study to investigate whether the observed effect can be attributed to respiratory inhibition instead of mitoK $\mathrm{ATP}_{\text {activity. }}$

It was reported almost forty years ago that at high doses diazoxide inhibits succinate dehydrogenase, complex II of the electron transport chain [85]. Indeed, all hydrophobic drugs including diazoxide (and pinacidil, another $\mathrm{K}_{\mathrm{ATP}}$ channel opener) exhibit concentration-dependent inhibition of the respiratory chain. This is due to their tendency to embed in the hydrophobic membrane and cause a plethora of effects. This is further supported by the observation that diazoxide is not entirely specific to SDH [129]. The results of the current study strongly suggest that diazoxide inhibits 
succinate-supported respiration at high doses $(\mathrm{IC} 50=110 \mu \mathrm{M})$ down to $30 \%$ respiratory activity at about $1 \mathrm{mM}$ diazoxide (figure 7 ), as previously described. However, these concentrations are in excess of those necessary to open mito $K_{\text {ATP }}$ (figure 6 ). In fact, the $\mathrm{K}_{1 / 2}$ for diazoxide mito $\mathrm{K}_{\mathrm{ATP}}$ opening is merely $3 \mu \mathrm{M}$ (Garlid 1996). In our studies, $30 \mu \mathrm{M}$ diazoxide is used in light scattering assays in order to ensure complete channel opening. Even at this concentration, no significant respiratory inhibition is observed.

At high concentrations 3-NPA acts as a suicide inhibitor of SDH by binding irreversibly to the enzyme and preventing it from further participating in its metabolic roles. Figure 9 demonstrates that the current study supports these claims; the IC50 $=1.05 \mathrm{mM}$. However, at much lower concentrations (10nM, figure 8) 3-NPA seems to be capable of opening mitoK $\mathrm{ATP}_{\text {. At }}$ At this low concentration, 3-NPA appears to have no effect on respiration. It is important to mention here that replicates are necessary to determine the exact dose range at which 3-NPA opens mitoK $_{\text {ATP }}$ in our light scattering system.

The influx of $\mathrm{K}+$ ions through mito $_{\mathrm{ATP}}$, observed as swelling during light scattering experiments, is a respiration driven process. The chemiosmotic gradient that is maintained by mitochondria during normal respiratory conditions is the same gradient that drives $\mathrm{K}+$ into the matrix. If the concentrations of diazoxide and 3-NPA that are used to open mitoK $\mathrm{K}_{\text {ATP }}$ inhibit respiration, then this swelling would not be observed (significantly decreased amount of swelling or even shrinkage would be observed), because inhibition of respiration decreases or abolishes this gradient. 
Some investigators [79] imply that the observed cardioprotection results from inhibition of SDH, since diazoxide, a known SDH inhibitor, has been used as a model mitoK $\mathrm{ATP}_{\mathrm{AP}}$ opener. However, my results demonstrate (figures $10 a-b, 11 a-b)$ that other mitoK $_{\text {ATP }}$ openers, such as PKG and

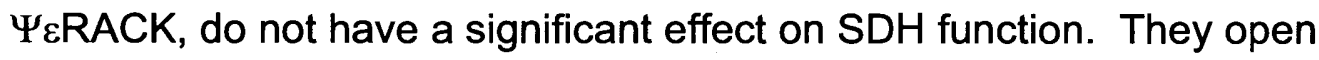
mitoK $_{\text {ATP }}$ at 0.25 units $/ \mu \mathrm{L}$ and $0.5 \mu \mathrm{M}$, respectively [68]. PKG and $\Psi \varepsilon R A C K$ do not activate mitoK $\mathrm{ATP}_{\text {directly, however, but act upstream of mitoK }}$ ATP in the cardioprotection pathway. This fact complicates the current issue and experiments with compounds that activate mitoK $\mathrm{ATP}_{\text {Airectly, but have no }}$ effect on any part of the respiratory chain, are necessary; such drugs were unavailable for the current study. Interestingly, glibenclamide, a drug used to inhibit $\mathrm{K}_{\text {ATP }}$ channel opening, is known to inhibit $\mathrm{SDH}$ as well as mitoK $\mathrm{K}_{\text {ATP }}$ opening, again demonstrating that that the mitoK $\mathrm{ATP}_{\mathrm{AP}}$ effect is not explained by SDH inhibition.

It has been suggested that ROS (reactive oxygen species) that are produced during respiratory inhibition are responsible for cardioprotection, giving a mechanism for cardioprotection via SDH inhibition. Indeed, ROS is central in all cardioprotection models, including the mitoK $\mathrm{K}_{\text {ATP }}$ hypothesis. A small amount of ROS, regardless of its origin, protects the heart from ischemia [49, 130-133]. This can be clearly demonstrated by including ROS scavengers in an assay that measures cardioprotection or mitoK $\mathrm{K}_{\text {ATP }}$ activity [131]. ROS scavengers also block preconditioning in Langendorff assays. In every case, the resulting effect is identical to that of 5-HD - abolition of 
cardioprotection. Small amounts of ROS are known to activate $\mathrm{PKC} \varepsilon$ by oxidizing the zinc fingers the enzyme and changing its conformation [134]. PKC $\varepsilon$ is a critical element in all modes of cardioprotection as it is thought to

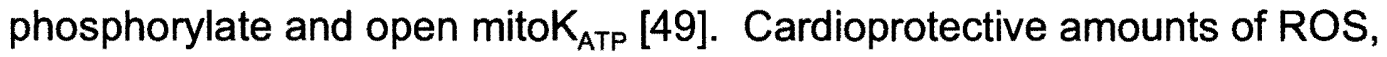

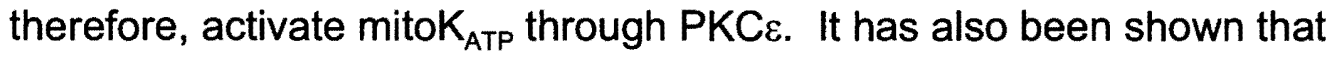
inhibition of the respiratory chain produces ROS [79]. It is therefore conceivable that the observed cardioprotective effect includes both slight respiratory inhibition and activation of mitoK $K_{\text {ATP. }}$. If mild inhibition causes some respiration inhibition and therefore causes a production of a small amount of ROS then this ROS could in turn activate and open mitoK $\mathrm{K}_{\text {ATP }}$ resulting in cardioprotection. In short, it is possible that diazoxide and 3-NPA, in small doses, inhibit respiration by an amount that does not cause apoptosis, but causes the production of a small amount of ROS which in turn activates $\mathrm{PKC} \varepsilon$, which finally activates mito $_{\mathrm{ATP}}$ and provides cardioprotection, and do not activate mitoK $\mathrm{K}_{\mathrm{ATP}}$ directly.

However, it is highly unlikely that the small amount of respiratory inhibition we observed in the mitoK $\mathrm{K}_{\mathrm{ATP}}$ opening doses has any effect on ROS production. In order to test above hypothesis, it would be necessary to measure ROS production after addition of 3-NPA and to test if, perhaps, marginal inhibition of SDH by an SDH-specific inhibitor (such as malonate) causes cardioprotection in situ. At this time there is no known mechanism by which SDH is capable of producing ROS, which is generally produced by 
Complex I and Complex III. In addition, recently, Drose et al [83] demonstrated that diazoxide does not generate ROS from the respiratory chain, making the above hypothesis even less likely. Controversy on this topic remains however, since Busija et al demonstrated that both 3-NPA and diazoxide increase mitochondrial ROS in the brain [135].

Ardehali et al have demonstrated that SDH is a part of a protein complex that is capable of transporting potassium ions, implying that $\mathrm{SDH}$ is in fact mitoK $_{\mathrm{ATP}}$, or that the two proteins are closely associatedb [136]. This group suggests that the ability of $\mathrm{SDH}$ to regulate mito $\mathrm{K}_{\mathrm{ATP}}$ activity is entirely independent from its function in the electron transport channel [136]. A very recent study by Wojtovich and Brookes provides additional evidence that

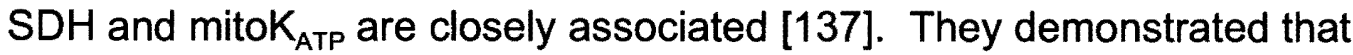
malonate, a competative inhibitor of $\mathrm{SDH}$, opens mitoK $\mathrm{ATP}_{\mathrm{AT}}$ channel even when the mitochondria are respiring on complex I substrates (glutamate and malate), at concentrations much lower than those necessary to inhibit SDH [137]. These data are in agreement with the dose-dependant effects of SDH inhibitors present in the current study. Interestingly, it has also been demonstrated that IPC decreases SDH activity [138]. From these data it can be speculated that during IPC or preconditioning by pharmacological agents, SDH decreases its function as a Citric Acid Cycle enzyme and electron transport chain enzyme and becomes involved in channeling potassium ions. This would also give an evolutionary reason for why SDH is imbedded in the inner membrane of the mitochondria. It is well established that the 
mitochondrial shape is highly dynamic thus quick volume regulation mechanism seems necessary. Although this hypothesis would explain why $\mathrm{SDH}$, which does not pump protons in the electron transport chain, is embedded in the membrane, it does not explain why some mitoK $\mathrm{ATP}_{\text {channel }}$ openers seem to have no effect on SDH and why some mitoK $\mathrm{K}_{\text {ATP }}$ channel closers also inhibit SDH activity. In order to test this hypothesis, it would be necessary to confirm the speculation that SDH is capable of shuttling $\mathrm{K}^{+}$and measure SDH enzymatic activity at the same time as $\mathrm{K}+$ transport (or mitoK $_{\text {ATP }}$ activity).

It is well known that many of the agents used in studying cardiac preconditioning have other effects on the heart, seemingly unrelated to their effects on the mito $K_{\text {ATP }}$ channel. It would be ideal to study the effects of these agents in situ, without disruption of cardiac myocytes. It is likely that mitochondrial isolation greatly disrupts the natural shape of each mitochondrion. At this point, unfortunately, there are no available techniques to do this.

The dose-response curves for both 3-NPA and diazoxide yielded a Hill slope that is greater than 1 (figures 7,9 ). It is important to point out that the system we tested is not an isolated one. Mitochondria purified in a crude, differential centrifugation manner was utilized in all our assays. Therefore, it is not feasible to create a perfect dose response curve with a Hill slope of 1 . For such an experiment, in order to describe the exact binding manner of drug to SDH, it would be necessary to work with isolated SDH. In both cases 
the Hill slope indicates some degree of cooperative binding. In fact, it is impossible to determine, in the present study, whether these drugs are acting only on SDH, and not having other unknown effects on the electron transport chain. Conceivably, it is possible that both diazoxide and 3-NPA affect other components of the electron transport chain causing an increase in ROS from complexes I or III. The current design of the study is, however, more relevant to the physiological conditions that we were attempting to assess. Additionally, the purpose of this study was not to obtain exact drug concentrations, but to assess whether or not succinate-supported respiration is significantly inhibited in doses that are used for mitoK $\mathrm{K}_{\text {ATP }}$ opening. 


\section{Conclusions}

Cardiac disease is the most common cause of death in the United States and in the world, therefore, understanding the details of its mechanism is of great importance to public health. Ischemic preconditioning, in particular, is an interesting phenomenon with a possibility of wide implications in the clinical field. Understanding how it works and how it can be manipulated is crucial.

The goal of the research presented in this thesis was to clarify if preconditioning by potassium channel openers is through the inhibition of succinate dehydrogenase, complex II of the electron chain, as has been claimed by some investigators, or if this kind of preconditioning is mediated by mitochondrial ATP-sensitive potassium channel. The results of this study indicate that the doses of potassium channel openers used to open mitoK $\mathrm{K}_{\mathrm{ATP}}$ in light scattering assays are insufficient to cause any significant respiratory inhibition. In addition, PKG and $\Psi \varepsilon R A C K$, which are known to open mitoK ${ }_{\text {ATP }}$ do not inhibit respiration at any dose tested.

Therefore, it appears that preconditioning by diazoxide, 3-NPA, PKG, and YERACK $_{\text {is }}$ mediated by mitoK $_{\text {ATP }}$ as previously suggested and not through the inhibition of succinate dehydrogenase. Many possible directions of further studies exist to clarify the exact mechanism of cardiac preconditioning. 


\section{References}

[1] W. Rosamond, K. Flegal, G. Friday, K. Furie, A. Go, K. Greenlund, N. Haase, M. Ho, V. Howard, B. Kissela, S. Kittner, D. Lloyd-Jones, M. McDermott, J. Meigs, C. Moy, G. Nichol, C.J. O'Donnell, V. Roger, J. Rumsfeld, P. Sorlie, J. Steinberger, T. Thom, S. Wasserthiel-Smoller and Y. Hong, Heart Disease and Stroke Statistics--2007 Update: A Report From the American Heart Association Statistics Committee and Stroke Statistics Subcommittee, Circulation 115 (2007) e69-171.

[2] J.M. Downey, A.M. Davis and M.V. Cohen, Signaling pathway in ischemic preconditioning, Heart Fail Rev 12 (2007) 181-8.

[3] G. Solaini and D.A. Harris, Biochemical dysfunction in heart mitochondria exposed to ischaemia and reperfusion., Biochem J 390 (2005) 377-94.

[4] G.P. Dobson and U.U. Himmelreich, Heart design: free ADP scales with absolute mitochondrial and myofibrillar volumes from mouse to human, Biochim Biophys Acta 1553 (2002) 261-7.

[5] A.P. Halestrap, S.J. Clarke and I. Khaliulin, The role of mitochondria in protection of the heart by preconditioning, Biochim Biophys Acta 1767 (2007) 1007-31.

[6] K. Vuorinen, K. Ylitalo, K. Peuhkurinen, P. Raatikainen, A. Ala-Rami and I.E. Hassinen, Mechanisms of Ischemic Preconditioning in Rat Myocardium : Roles of Adenosine, Cellular Energy State, and Mitochondrial F1Fo-ATPase, Circulation 91 (1995) 2810-8.

[7] G. Ambrosio, J.L. Zweier, C. Duilio, P. Kuppusamy, G. Santoro, P.P. Elia, I. Tritto, P. Cirillo, M. Condorelli, M. Chiariello and et al., Evidence that mitochondrial respiration is a source of potentially toxic oxygen free radicals in intact rabbit hearts subjected to ischemia and reflow, $\mathrm{J}$ Biol Chem. 268 (1993) 18532-41.

[8] M. Lazdunski, C. Frelin and P.U. Vigne, The sodium/hydrogen exchange system in cardiac cells: Its biochemical and pharmacological properties and its role in regulating internal concentrations of sodium and internal pH, J Mol Cell Cardiol. 17 (1985) 1029-42.

[9] C. Frelin, P. Vigne and M. Lazdunski, The role of the $\mathrm{Na}+/ \mathrm{H}+$ 
exchange system in cardiac cells in relation to the control of the internal $\mathrm{Na}+$ concentration. A molecular basis for the antagonistic effect of ouabain and amiloride on the heart, J Biol Chem 259 (1984) 8880-5.

[10] M. Tani and J. Neely, Role of intracellular $\mathrm{Na}+$ in $\mathrm{Ca} 2+$ overload and depressed recovery of ventricular function of reperfused ischemic rat hearts. Possible involvement of $\mathrm{H}+-\mathrm{Na}+$ and $\mathrm{Na}+-\mathrm{Ca} 2+$ exchange, Circ Res 65 (1989) 1045-56.

[11] R. Vaughan-Jones and $\mathrm{M}$. Wu, Extracellular $\mathrm{H}+$ inactivation of $\mathrm{Na}(+)-$ $\mathrm{H}+$ exchange in the sheep cardiac Purkinje fibre, J Physiol (Lond) 428 (1990) 441-66.

[12] H.H. Klein, S. Pich, R.M. Bohle, S. Lindert-Heimberg and K. Nebendahl, $\mathrm{Na}+/ \mathrm{H}+$ Exchange Inhibitor Cariporide Attenuates Cell Injury Predominantly During Ischemia and Not at Onset of Reperfusion in Porcine Hearts With Low Residual Blood Flow, Circulation 102 (2000) 1977-82.

[13] L.B. Becker, New concepts in reactive oxygen species and cardiovascular reperfusion physiology, Cardiovasc Res 61 (2004) 46170.

[14] L.G. Kevin, P. Katz, A.K. Camara, E. Novalija, M.L. Riess and D.F. Stowe, Anesthetic preconditioning: effects on latency to ischemic injury in isolated hearts, Anesthesiology 99 (2003) 385-91.

[15] P. Eaton, H.L. Byers, N. Leeds, M.A. Ward and M.J. Shattock, Detection, quantitation, purification, and identification of cardiac proteins S-thiolated during ischemia and reperfusion, J Biol Chem 277 (2002) 9806-11.

[16] L.C. Hool, Reactive oxygen species in cardiac signalling: from mitochondria to plasma membrane ion channels, Clin Exp Pharmacol Physiol 33 (2006) 146-51.

[17] H.M. Honda, P. Korge and J.N. Weiss, Mitochondria and ischemia/reperfusion injury, Ann N Y Acad Sci 1047 (2005) 248-58.

[18] R.A. Gottlieb, Mitochondria and apoptosis, Biol Signals Recept 10 (2001) 147-61.

[19] R.A. Gottlieb, Mitochondrial signaling in apoptosis: mitochondrial daggers to the breaking heart, Basic Res Cardiol 98 (2003) 242-9. 
[20] E. Doran and A.P. Halestrap, Cytochrome c release from isolated rat liver mitochondria can occur independently of outer-membrane rupture: possible role of contact sites, Biochem J 348 (2000) 343-50.

[21] S.E. Logue, A.B. Gustafsson, A. Samali and R.A. Gottlieb, Ischemia/reperfusion injury at the intersection with cell death, J Mol Cell Cardiol 38 (2005) 21-33.

[22] C.E. Murry, R.B. Jennings and K.A. Reimer, Preconditioning with ischemia: a delay of lethal cell injury in ischemic myocardium, Circulation 74 (1986) 1124-36.

[23] N. Kaeffer, V. Richard, A. Francois, F. Lallemand, J.P. Henry and C. Thuillez, Preconditioning prevents chronic reperfusion-induced coronary endothelial dysfunction in rats, Am J Physiol Heart Circ Physiol 271 (1996) H842-9.

[24] D.M. Yellon and J.M. Downey, Preconditioning the Myocardium: From Cellular Physiology to Clinical Cardiology, Physiol Rev 83 (2003) 111351.

[25] R.C. Kukreja, F. Salloum, A. Das, R. Ockaili, C. Yin, Y.A. Bremer, P.W. Fisher, M. Wittkamp, J. Hawkins, E. Chou, A.K. Kukreja, X. Wang, V.R. Marwaha and L. Xi, Pharmacological preconditioning with sildenafil: Basic mechanisms and clinical implications, Vascul Pharmacol 42 (2005) 219-32.

[26] D.R. Meldrum, J.C.J. Cleveland, M.B. Mitchell, R.T. Rowland, A. Banerjee and A.H. Harken, Constructive priming of myocardium against ischemia-reperfusion injury, Shock 6 (1996) 238-42.

[27] G.J. Grover, J.R. McCullough, D.E. Henry, M.L. Conder and P.G. Sleph, Anti-ischemic effects of the potassium channel activators pinacidil and cromakalim and the reversal of these effects with the potassium channel blocker glyburide, J Pharmacol Exp Ther 251 (1989) 98-104.

[28] R.J. Gumina, E. Buerger, C. Eickmeier, J. Moore, J. Daemmgen and G.J. Gross, Inhibition of the $\mathrm{Na}(+) / \mathrm{H}(+)$ exchanger confers greater cardioprotection against 90 minutes of myocardial ischemia than ischemic preconditioning in dogs, Circulation 100 (1999) 2519-26; discussion 2469-72.

[29] R.M. Mentzer, Jr., R.D. Lasley, A. Jessel and M. Karmazyn, Intracellular sodium hydrogen exchange inhibition and clinical 
myocardial protection, Ann Thorac Surg 75 (2003) S700-8.

[30] Z.Q. Zhao, J.S. Corvera, M.E. Halkos, F. Kerendi, N.P. Wang, R.A. Guyton and J. Vinten-Johansen, Inhibition of myocardial injury by ischemic post-conditioning during reperfusion: comparison with ischemic preconditioning, Am J Physiol 3 (2003) 3.

[31] J.P. Arena and R.S. Kass, Block of heart potassium channels by clofilium and its tertiary analogs: relationship between drug structure and type of channel blocked, Mol Pharmacol 34 (1988) 60-6.

[32] W. Osterrieder, Modification of $\mathrm{K}+$ conductance of heart cell membrane by BRL 34915, Naunyn Schmiedebergs Arch Pharmacol 337 (1988) 93-7.

[33] H. Schmid-Antomarchi, J. De Weille, M. Fosset and M. Lazdunski, The receptor for antidiabetic sulfonylureas controls the activity of the ATPmodulated K+ channel in insulin-secreting cells, J Biol Chem 262 (1987) 15840-4.

[34] G.J. Gross, D.C. Warltier and H.F. Hardman, Comparative effects of nicorandil, a nicotinamide nitrate derivative, and nifedipine on myocardial reperfusion injury in dogs, J Cardiovasc Pharmacol 10 (1987) 535-42.

[35] G.J. Grover, S. Dzwonczyk, C.S. Parham and P.G. Sleph, The protective effects of cromakalim and pinacidil on reperfusion function and infarct size in isolated perfused rat hearts and anesthetized dogs, Cardiovasc Drugs Ther 4 (1990) 465-74.

[36] G.J. Grover, J. Newburger, P.G. Sleph, S. Dzwonczyk, S.C. Taylor, S.Z. Ahmed and K.S. Atwal, Cardioprotective effects of the potassium channel opener cromakalim: stereoselectivity and effects on myocardial adenine nucleotides, J Pharmacol Exp Ther 257 (1991) 156-62.

[37] W.C. Cole, C.D. McPherson and D. Sontag, ATP-regulated K+ channels protect the myocardium against ischemia/reperfusion damage, Circ Res 69 (1991) 571-81.

[38] H. Ohta, Y. Jinno, K. Harada, N. Ogawa, H. Fukushima and K. Nishikori, Cardioprotective effects of KRN2391 and nicorandil on ischemic dysfunction in perfused rat heart, Eur J Pharmacol 204 (1991) 171-7. 
[39] M. Galinanes, M.J. Shattock and D.J. Hearse, Effects of potassium channel modulation during global ischaemia in isolated rat heart with and without cardioplegia, Cardiovasc Res 26 (1992) 1063-8.

[40] H.L. Tan, P. Mazon, H.J. Verberne, M.E. Sleeswijk, R. Coronel, T. Opthof and M.J. Janse, Ischaemic preconditioning delays ischaemia induced cellular electrical uncoupling in rabbit myocardium by activation of ATP sensitive potassium channels, Cardiovasc Res 27 (1993) 644-51.

[41] G.J. Grover, Protective effects of ATP sensitive potassium channel openers in models of myocardial ischaemia, Cardiovasc Res 28 (1994) 778-82.

[42] G.J. Grover, A.J. D'Alonzo, C.S. Parham and R.B. Darbenzio, Cardioprotection with the KATP opener cromakalim is not correlated with ischemic myocardial action potential duration, $\mathrm{J}$ Cardiovasc Pharmacol 26 (1995) 145-52.

[43] G.J. Gross, ATP-sensitive potassium channels and myocardial preconditioning, Basic Res Cardiol 90 (1995) 85-8.

[44] J.F. Faivre and I. Findlay, Effects of tolbutamide, glibenclamide and diazoxide upon action potentials recorded from rat ventricular muscle, Biochim Biophys Acta 984 (1989) 1-5.

[45] I. Inoue, H. Nagase, K. Kishi and T. Higuti, ATP-sensitive K+ channel in the mitochondrial inner membrane, Nature 352 (1991) 244-7.

[46] P. Paucek, G. Mironova, F. Mahdi, A.D. Beavis, G. Woldegiorgis and K.D. Garlid, Reconstitution and partial purification of the glibenclamidesensitive, ATP-dependent $\mathrm{K}^{+}$channel from rat liver and beef heart mitochondria, J Biol Chem 267 (1992) 26062-9.

[47] K.D. Garlid, P. Paucek, V. Yarov-Yarovoy, X. Sun and P.A. Schindler, The mitochondrial $K_{\text {ATP }}$ channel as a receptor for potassium channel openers, J Biol Chem 271 (1996) 8796-9.

[48] K.D. Garlid, P. Paucek, V. Yarov-Yarovoy, H.N. Murray, R.B. Darbenzio, A.J. D'Alonzo, N.J. Lodge, M.A. Smith and G.J. Grover, Cardioprotective effect of diazoxide and its interaction with mitochondrial ATP-sensitive $\mathrm{K}^{+}$channels. Possible mechanism of cardioprotection, Circ Res 81 (1997) 1072-82.

[49] A.D. Costa, R. Jakob, C.L. Costa, K. Andrukhiv, I.C. West and K.D. 
Garlid, The mechanism by which the mitochondrial ATP-sensitive K+ channel opening and $\mathrm{H} 2 \mathrm{O} 2$ inhibit the mitochondrial permeability transition, J Biol Chem 281 (2006) 20801-8.

[50] J.D. McCully and S. Levitsky, The mitochondrial K(ATP) channel and cardioprotection, Ann Thorac Surg 75 (2003) S667-73.

[51] B. O'Rourke, Evidence for mitochondrial $\mathrm{K}+$ channels and their role in cardioprotection, Circ Res 94 (2004) 420-32.

[52] O. Oldenburg, M.V. Cohen, D.M. Yellon and J.M. Downey, Mitochondrial $\mathrm{K}_{\mathrm{ATP}}$ channels: role in cardioprotection, Cardiovasc Res 55 (2002) 429-37.

[53] G.J. Gross and R.M. Fryer, Sarcolemmal versus mitochondrial ATPsensitive K+ channels and myocardial preconditioning, Circ Res 84 (1999) 973-9.

[54] Y. Liu, T. Sato, B. O'Rourke and E. Marban, Mitochondrial ATPdependent potassium channels: novel effectors of cardioprotection?, Circulation 97 (1998) 2463-9.

[55] T. Sato, B. O'Rourke and E. Marbán, Modulation of mitochondrial ATP-dependent $\mathrm{K}^{+}$channels by protein kinase C, Circ Res 83 (1998) 110-4.

[56] K.D. Garlid, P. Dos Santos, Z.-J. Xie, A.D.T. Costa and P. Paucek, Mitochondrial potassium transport: the role of the mitochondrial ATPsensitive $\mathrm{K}^{+}$channel in cardiac function and cardioprotection, Biochim Biophys Acta 1606 (2003) 1-21.

[57] J. Liu, J. Tian, M. Haas, J.I. Shapiro, A. Askari and Z. Xie, Ouabain interaction with cardiac $\mathrm{Na}+/ \mathrm{K}+-\mathrm{ATP}$ ase initiates signal cascades independent of changes in intracellular $\mathrm{Na}+$ and $\mathrm{Ca} 2+$ concentrations, J Biol Chem 275 (2000) 27838-44.

[58] J. Tian, J. Liu, K.D. Garlid, J.I. Shapiro and Z. Xie, Involvement of Mitogen-activated Protein Kinases and Reactive Oxygen Species in the Inotropic Action of Ouabain on Cardiac Myocytes. A Potential Role for Mitochondrial $K_{\text {ATP }}$ Channels, Mol Cell Biochem 242 (2003) 181187.

[59] H. Hauner, Insulin resistance and the metabolic syndrome-a challenge of the new millennium, Eur J Clin Nutr 56 (2002) S25-9. 
[60] D.J. Hausenloy, A. Tsang, M.M. Mocanu and D.M. Yellon, Ischemic preconditioning protects by activating prosurvival kinases at reperfusion, Am J Physiol 288 (2005) H971-6.

[61] D.J. Hausenloy, A. Tsang and D.M. Yellon, The reperfusion injury salvage kinase pathway: a common target for both ischemic preconditioning and postconditioning, Trends Cardiovasc Med 15 (2005) 69-75.

[62] P. Korge, H.M. Honda and J.N. Weiss, Regulation of the mitochondrial permeability transition by matrix $\mathrm{Ca}(2+)$ and voltage during anoxia/reoxygenation, Am J Physiol 280 (2001) C517-26.

[63] P. Korge, H.M. Honda and J.N. Weiss, Protection of cardiac mitochondria by diazoxide and protein kinase C: implications for ischemic preconditioning, Proc Natl Acad Sci U S A 99 (2002) 3312-7.

[64] C.P. Baines, C.X. Song, Y.T. Zheng, G.W. Wang, J. Zhang, O.L. Wang, Y. Guo, R. Bolli, E.M. Cardwell and P. Ping, Protein kinase Cepsilon interacts with and inhibits the permeability transition pore in cardiac mitochondria, Circ Res 92 (2003) 873-80.

[65] K. Inagaki, R. Begley, F. Ikeno and D. Mochly-Rosen, Cardioprotection by epsilon-protein kinase $\mathrm{C}$ activation from ischemia: continuous delivery and antiarrhythmic effect of an epsilon-protein kinase Cactivating peptide, Circulation 111 (2005) 44-50.

[66] A.T. Saurin, D.J. Pennington, N.J. Raat, D.S. Latchman, M.J. Owen and M.S. Marber, Targeted disruption of the protein kinase $C$ epsilon gene abolishes the infarct size reduction that follows ischaemic preconditioning of isolated buffer-perfused mouse hearts, Cardiovasc Res 55 (2002) 672-80.

[67] J.S. Kim, S. Ohshima, P. Pediaditakis and J.J. Lemasters, Nitric oxide protects rat hepatocytes against reperfusion injury mediated by the mitochondrial permeability transition, Hepatology 39 (2004) 1533-43.

[68] A.D. Costa, K.D. Garlid, I.C. West, T.M. Lincoln, J.M. Downey, M.V. Cohen and S.D. Critz, Protein Kinase G Transmits the Cardioprotective Signal From Cytosol to Mitochondria, Circ Res 97 (2005) 329-36.

[69] A. Andrukhiv, A.D. Costa, I.C. West and K.D. Garlid, Opening mitoKATP increases superoxide generation from Complex I of the electron transport chain, Am J Physiol Heart Circ Physiol (2006) 
H2067-2074.

[70] K.D. Garlid. in (Lemasters, J.J., Hackenbrock, C.R., Thurman, R.G. and Westerhoff, H.V., eds.) Integration of Mitochondrial Function, Plenum Publishing Corp., New York 1988, pp. 257-276.

[71] A.J. Kowaltowski, S. Seetharaman, P. Paucek and K.D. Garlid, Bioenergetic consequences of opening the ATP-sensitive $\mathrm{K}^{+}$channel of heart mitochondria, Am J Physiol 280 (2001) H649-57.

[72] K.D. Garlid, A.D. Beavis and S.K. Ratkje, On the nature of ion leaks in energy-transducing membranes, Biochim Biophys Acta 976 (1989) 109-20.

[73] Q. Huang, S. Bu, Y. Yu, Z. Guo, G. Ghatnekar, M. Bu, L. Yang, B. Lu, Z. Feng, S. Liu and F. Wang, Diazoxide prevents diabetes through inhibiting pancreatic beta-cells from apoptosis via $\mathrm{Bcl}-2 / \mathrm{Bax}$ rate and p38-beta mitogen-activated protein kinase, Endocrinology 148 (2007) 81-91.

[74] Y. Li, V. Sharov, N. Jiang, C. Zaloga, H. Sabbah and M. Chopp, Ultrastructural and light microscopic evidence of apoptosis after middle cerebral artery occlusion in the rat, Am J Pathol 146 (1995) 10451051.

[75] R. Bajgar, S. Seetharaman, A.J. Kowaltowski, K.D. Garlid and P. Paucek, Identification and properties of a novel intracellular (mitochondrial) ATP-sensitive potassium channel in brain, J Biol Chem 276 (2001) 33369-74.

[76] F. Domoki, J.V. Perciaccante, R. Veltkamp, F. Bari and D.W. Busija, Mitochondrial potassium channel opener diazoxide preserves neuronal-vascular function after cerebral ischemia in newborn pigs, Stroke 30 (1999) 2713-8; discussion 2718-9.

[77] J.G. Shake, E.A. Peck, E. Marban, V.L. Gott, M.V. Johnston, J.C. Troncoso, J.M. Redmond and W.A. Baumgartner, Pharmacologically induced preconditioning with diazoxide: a novel approach to brain protection, Ann Thorac Surg 72 (2001) 1849-54.

[78] Y. Teshima, M. Akao, R.A. Li, T.H. Chong, W.A. Baumgartner, M.V. Johnston and E. Marban, Mitochondrial ATP-sensitive potassium channel activation protects cerebellar granule neurons from apoptosis induced by oxidative stress, Stroke 34 (2003) 1796-802. 
[79] J. Minners, L. Lacerda, D. Yellon, L. Opie, C. McLeod and M. Sack, Diazoxide-induced respiratory inhibition -- a putative mitochondrial KATP channel independent mechanism of pharmacological preconditioning, Mol Cell Biochem 294 (2007) 11-8.

[80] C. Ozcan, M. Bienengraeber, P.P. Dzeja and A. Terzic, Potassium channel openers protect cardiac mitochondria by attenuating oxidant stress at reoxygenation, Am J Physiol Heart Circ Physiol 282 (2002) H531-9.

[81] P.J. Hanley, M. Mickel, M. Loffler, U. Brandt and J. Daut, $\mathrm{K}_{\text {ATP }}$ channelindependent targets of diazoxide and 5-hydroxydecanoate in the heart, J Physiol 542 (2002) 735-41.

[82] K.H. Lim, S.A. Javadov, M. Das, S.J. Clarke, M.S. Suleiman and A.P. Halestrap, The effects of ischaemic preconditioning, diazoxide and 5hydroxydecanoate on rat heart mitochondrial volume and respiration, $\mathrm{J}$ Physiol 545 (2002) 961-74.

[83] S. Drose, U. Brandt and P.J. Hanley, K+-independent Actions of Diazoxide Question the Role of Inner Membrane KATP Channels in Mitochondrial Cytoprotective Signaling, J Biol Chem. 281 (2006) 23733-9.

[84] P.J. Hanley and J. Daut, K(ATP) channels and preconditioning: a reexamination of the role of mitochondrial K(ATP) channels and an overview of alternative mechanisms, J Mol Cell Cardiol 39 (2005) 1750.

[85] G. Schafer, C. Wegener, R. Portenhauser and D. Bojanovski, Diazoxide, an inhibitor of succinate oxidation, Biochem Pharmacol 18 (1969) 2678-81.

[86] K. Moritani, T. Miyazaki, S. Miyoshi, M. Asanagi, L.S. Zhao, H. Mitamura and S. Ogawa, Blockade of ATP-sensitive potassium channels by 5-hydroxydecanoate suppresses monophasic action potential shortening during regional myocardial ischemia, Cardiovasc Drugs Ther 8 (1994) 749-56.

[87] J. Munch-Ellingsen, J.E. Lokebo, E. Bugge, A.K. Jonassen, T. Ravingerova and $\mathrm{K}$. Ytrehus, 5-HD abolishes ischemic preconditioning independently of monophasic action potential duration in the heart, Basic Res Cardiol 95 (2000) 228-34.

[88] M. Krenz, O. Oldenburg, H. Wimpee, M.V. Cohen, K.D. Garlid, S.D. 
Critz, J.M. Downey and J.N. Benoit, Opening of ATP-sensitive potassium channels causes generation of free radicals in vascular smooth muscle cells, Basic Res Cardiol 97 (2002) 365-73.

[89] M.P. Morris, C. Pagan and H.E. Warmke, Hiptagenic Acid, a Toxic Component of Indigofera endecaphylla, Science 119 (1954) 322-3.

[90] T.A. Alston, L. Mela and H.J. Bright, 3-Nitropropionate, the Toxic Substance of Indigofera, is a Suicide Inactivator of Succinate Dehydrogenase, Proc Natl Acad Sci U S A 74 (1977) 3767-71.

[91] P.A. Nony, A.C. Scallet, R.L. Rountree, X. Ye and Z. Binienda, 3Nitropropionic acid (3-NPA) produces hypothermia and inhibits histochemical labeling of succinate dehydrogenase (SDH) in rat brain, Metab Brain Dis 14 (1999) 83-94.

[92] L.F. James, W.J. Hartley, M.C. Williams and K.R. Van Kampen, Field and experimental studies in cattle and sheep poisoned by nitro-bearing Astragalus or their toxins, Am J Vet Res 41 (1980) 377-82.

[93] A.C. Ludolph, M. Seelig, A.G. Ludolph, M.I. Sabri and P.S. Spencer, ATP deficits and neuronal degeneration induced by 3-nitropropionic acid, Ann N Y Acad Sci 648 (1992) 300-2.

[94] C.J. Coles, D.E. Edmondson and T.P. Singer, Inactivation of succinate dehydrogenase by 3-nitropropionate, J Biol Chem 254 (1979) 5161-7.

[95] M.W. Riepe and A.C. Ludolph, Chemical preconditioning: a cytoprotective strategy, Mol Cell Biochem 174 (1997) 249-54.

[96] F. Wiegand, W. Liao, C. Busch, S. Castell, F. Knapp, U. Lindauer, D. Megow, A. Meisel, A. Redetzky, K. Ruscher, G. Trendelenburg, I. Victorov, M. Riepe, H.C. Diener and U. Dirnagl, Respiratory chain inhibition induces tolerance to focal cerebral ischemia, J Cereb Blood Flow Metab 19 (1999) 1229-37.

[97] A.M. Brambrink, A. Schneider, H. Noga, A. Astheimer, B. Gotz, I. Korner, A. Heimann, M. Welschof and O. Kempski, ToleranceInducing dose of 3-nitropropionic acid modulates bcl-2 and bax balance in the rat brain: a potential mechanism of chemical preconditioning, J Cereb Blood Flow Metab 20 (2000) 1425-36.

[98] M. Erecinska and D. Nelson, Effects of 3-Nitropropionic Acid on Synaptosomal Energy and Transmitter Metabolism: Relevance to Neurodegenerative Brain Diseases, J Neurochem 63 (1994) 1033-41. 
[99] Z. Pang and J.W. Geddes, Mechanisms of cell death induced by the mitochondrial toxin 3-nitropropionic acid: acute excitotoxic necrosis and delayed apoptosis, J Neurosci 17 (1997) 3064-73.

[100] H. Sato, T. Miki, R.P. Vallabhapurapu, P. Wang, G.S. Liu, M.V. Cohen and J.M. Downey, The mechanism of protection from 5 ( $\mathrm{N}$-ethyl-Nisopropyl)amiloride differs from that of ischemic preconditioning in rabbit heart, Basic Research In Cardiology 92 (1997) 339-50.

[101] M. Riepe, N. Hori, A.C. Ludolph, D.O. Carpenter, P.S. Spencer and C.N. Allen, Inhibition of energy metabolism by 3-nitropropionic acid activates ATP-sensitive potassium channels, Brain Res 586 (1992) 616.

[102] T. Horiguchi, B. Kis, N. Rajapakse, K. Shimizu and D.W. Busija, Opening of mitochondrial ATP-sensitive potassium channels is a trigger of 3-nitropropionic acid-induced tolerance to transient focal cerebral ischemia in rats, Stroke 34 (2003) 1015-20.

[103] Z. Hu, Y. Yang, K. Zhang and Z. Sun, Chemical preconditioning by 3nitropropionic acid reduces ischemia-reperfusion injury in rat heart, $\mathrm{J}$ Huazhong Univ Sci Technolog Med Sci 25 (2005) 439-41.

[104] R.A. Ockaili, P. Bhargava and R.C. Kukreja, Chemical preconditioning with 3-nitropropionic acid in hearts: role of mitochondrial $\mathrm{K}_{\text {ATP }}$ channel, Am J Physiol 280 (2001) H2406-11.

[105] U. Panten, J. Burgfeld, F. Goerke, M. Rennicke, M. Schwanstecher, A. Wallasch, B.J. Zunkler and S. Lenzen, Control of insulin secretion by sulfonylureas, meglitinide and diazoxide in relation to their binding to the sulfonylurea receptor in pancreatic islets, Biochem Pharmacol 38 (1989) 1217-29.

[106] J. Varon and P.E. Marik, The Diagnosis and Management of Hypertensive Crises, Chest 118 (2000) 214-27.

[107] E.A. Belyaeva, A. Szewczyk, B. Mikolajek, M.J. Nalecz and L. Wojtczak, Demonstration of glibenclamide-sensitive $\mathrm{K}+$ fluxes in rat liver mitochondria, Biochem Mol Biol Int 31 (1993) 493-500.

[108] A. Szewczyk, G. Wojcik and M.J. Nalecz, Potassium channel opener, RP 66471, induces membrane depolarization of rat liver mitochondria, Biochem Biophys Res Commun 207 (1995) 126-32.

[109] N.S. Cook and U. Quast, Potassium channel pharmacology., In: 
Potassium channels (Cook, N.S., ed.) Ellis Harwood Ltd., pp 181-231. (1990).

[110] C.P. Baines, J. Zhang, G.-W. Wang, Y.-T. Zheng, J.X. Xiu, E.M. Cardwell, R. Bolli and P. Ping, Mitochondrial PKC • and MAPK form signaling modules in the murine heart: enhanced mitochondrial PKC• MAPK interactions and differential MAPK activation in PKC• -induced cardioprotection, Circ Res 90 (2002) 390-7.

[111] L. Chen, H. Hahn, G. Wu, C.H. Chen, T. Liron, D. Schechtman, G. Cavallaro, L. Banci, Y. Guo, R. Bolli, G.W. Dorn, 2nd and D. MochlyRosen, Opposing cardioprotective actions and parallel hypertrophic effects of delta PKC and epsilon PKC, Proc Natl Acad Sci U S A 98 (2001) 11114-9.

[112] D. Guo, T. Nguyen, M. Ogbi, H. Tawfik, G. Ma, Q. Yu, R.W. Caldwell and J.A. Johnson, Protein kinase C-epsilon coimmunoprecipitates with cytochrome oxidase subunit IV and is associated with improved cytochrome-c oxidase activity and cardioprotection, Am J Physiol Heart Circ Physiol 293 (2007) H2219-30.

[113] K. Inagaki, H.S. Hahn, G.W. Dorn, 2nd and D. Mochly-Rosen, Additive protection of the ischemic heart ex vivo by combined treatment with delta-protein kinase $C$ inhibitor and epsilon-protein kinase $C$ activator, Circulation 108 (2003) 869-75.

[114] P. Ping, J. Zhang, Y. Qiu, X.L. Tang, S. Manchikalapudi, X. Cao and $R$. Bolli, Ischemic preconditioning induces selective translocation of protein kinase $\mathrm{C}$ isoforms epsilon and eta in the heart of conscious rabbits without subcellular redistribution of total protein kinase $\mathrm{C}$ activity, Circ Res 81 (1997) 404-14.

[115] G.W. Dorn, M.C. Souroujon, T. Liron, C.H. Chen, M.O. Gray, H.Z. Zhou, M. Csukai, G. Wu, J.N. Lorenz and D. Mochly Rosen, Sustained in vivo cardiac protection by a rationally designed peptide that causes epsilon protein kinase C translocation, Proc Natl Acad Sci U S A 96 (1999) 12798-803.

[116] A. Nakano, M.V. Cohen and J.M. Downey, Ischemic preconditioning. From basic mechanisms to clinical applications, Pharmacol Ther 86 (2000) 263-75.

[117] A. Das, A. Smolenski, S.M. Lohmann and R.C. Kukreja, Cyclic GMPdependent Protein Kinase I\{alpha\} Attenuates Necrosis and Apoptosis Following Ischemia/Reoxygenation in Adult Cardiomyocyte, J. Biol. 
Chem. 281 (2006) 38644-52.

[118] T.M. Lincoln, N. Dey and H. Sellak, Signal Transduction in Smooth Muscle: Invited Review: cGMP-dependent protein kinase signaling mechanisms in smooth muscle: from the regulation of tone to gene expression, J Appl Physiol 91 (2001) 1421-30.

[119] F. Hofmann, A. Ammendola and J. Schlossmann, Rising behind NO: cGMP-dependent protein kinases, J Cell Sci 113 (2000) 1671-6.

[120] J. Han, N. Kim, E. Kim, W.-K. Ho and Y.E. Earm, Modulation of ATPsensitive Potassium Channels by cGMP-dependent Protein Kinase in Rabbit Ventricular Myocytes, J Biol Chem 276 (2001) 22140-7.

[121] O. Oldenburg, Q. Qin, T. Krieg, X.-M. Yang, S. Philipp, S.D. Critz, M.V. Cohen and J.M. Downey, Bradykinin induces mitochondrial ROS generation via NO, cGMP, PKG, and mitoK $_{\text {ATP }}$ channel opening and leads to cardioprotection, Am J Physiol 286 (2004) H468-76.

[122] A.G. Gornall, C.J. Bardawill and M.M. David, Determination of serum proteins by means of the biuret reaction, J Biol Chem 177 (1949) 75166.

[123] A.D. Beavis, R.D. Brannan and K.D. Garlid, Swelling and contraction of the mitochondrial matrix. I. A structural interpretation of the relationship between light scattering and matrix volume, J Biol Chem 260 (1985) 13424-33.

[124] H. Tedeschi and D.L. Harris, The osmotic behavior and permeability to non-electrolytes of mitochondria, Arch Biochem Biophys 58 (1955) 5267.

[125] G.J. Gross and J.A. Auchampach, Role of ATP dependent potassium channels in myocardial ischaemia, Cardiovasc Res 26 (1992) 1011-6.

[126] M.E. Speechly-Dick, G.J. Grover and D.M. Yellon, Does ischemic preconditioning in the human involve protein kinase $C$ and the ATPdependent $\mathrm{K}+$ channel? Studies of contractile function after simulated ischemia in an atrial in vitro model, Circ Res 77 (1995) 1030-5.

[127] R.A. Kloner, R. Bolli, E. Marban, L. Reinlib and E. Braunwald, Medical and cellular implications of stunning, hibernation, and preconditioning: an NHLBI workshop, Circulation 97 (1998) 1848-67.

[128] J.P.t. Clement, K. Kunjilwar, G. Gonzalez, M. Schwanstecher, U. 
Panten, L. Aguilar-Bryan and J. Bryan, Association and stoichiometry of K(ATP) channel subunits, Neuron 18 (1997) 827-38.

[129] M.J. MacDonald, The use of calcium uptake by small amounts of mitochondria from pancreatic islets to study mitochondrial respiration: the effects of diazoxide and sodium, Biochem Int 8 (1984) 771-8.

[130] D.K. Das, N. Maulik, M. Sato and P.S. Ray, Reactive oxygen species function as second messenger during ischemic preconditioning of heart, Mol Cell Biochem 196 (1999) 59-67.

[131] R.A. Forbes, C. Steenbergen and E. Murphy, Diazoxide-Induced Cardioprotection Requires Signaling Through a Redox-Sensitive Mechanism, Circ Res 88 (2001) 802-9.

[132] I. Tritto, D. D'Andrea, N. Eramo, A. Scognamiglio, C. De Simone, A. Violante, A. Esposito, M. Chiariello and G. Ambrosio, Oxygen radicals can induce preconditioning in rabbit hearts, Circ Res 80 (1997) 743-8.

[133] O. Oldenburg, S.D. Critz, M.V. Cohen and J.M. Downey, Acetylcholine-induced production of reactive oxygen species in adult rabbit ventricular myocytes is dependent on phosphatidylinositol 3- and Src-kinase activation and mitochondrial $\mathrm{K}_{\text {ATP }}$ channel opening, $\mathrm{J}$ Mol Cell Cardiol 35 (2003) 653-60.

[134] I. Korichneva, B. Hoyos, R. Chua, E. Levi and U. Hammerling, Zinc release from protein kinase $C$ as the common event during activation by lipid second messenger or reactive oxygen, J Biol Chem 277 (2002) 44327-31.

[135] D.W. Busija, P. Katakam, N.C. Rajapakse, B. Kis, G. Grover, F. Domoki and F. Bari, Effects of ATP-sensitive potassium channel activators diazoxide and BMS-191095 on membrane potential and reactive oxygen species production in isolated piglet mitochondria, Brain Res Bull 66 (2005) 85-90. 